Mens

revue d'histoire intellectuelle de l'Amérique française

\title{
D’un catholicisme à l'autre : trois ordres catholiques au Québec et leurs revues face à l'Aggiornamento, 1962-1970
}

\section{Janine Thériault}

Volume 5, numéro 1, automne 2004

URI : https://id.erudit.org/iderudit/1024388ar

DOI : https://doi.org/10.7202/1024388ar

Aller au sommaire du numéro

Éditeur(s)

Centre de recherche en civilisation canadienne-française

ISSN

1492-8647 (imprimé)

1927-9299 (numérique)

Découvrir la revue

Citer cet article

Thériault, J. (2004). D’un catholicisme à l'autre : trois ordres catholiques au Québec et leurs revues face à l'Aggiornamento, 1962-1970. Mens, 5(1), 7-71. https://doi.org/10.7202/1024388ar

\section{Résumé de l'article}

Le texte qui suit examine le processus de passage d'une forme de catholicisme, celui de l'après-concile de Trente, à celui qui se pratique au Québec depuis le concile Vatican II. Il s'agit principalement d'évaluer le degré d'adaptation de l'Église catholique québécoise à la modernité contemporaine et, en l'occurrence, trois revues en seront les témoins : Relations, publiée par les Pères jésuites, Culture, par les Pères franciscains et Maintenant, par les Pères dominicains. L'étude porte principalement sur les années 1962 à 1970, ce qui est d'autant plus intéressant qu'une polarité idéologique opposait alors la pensée des Jésuites à celle des Dominicains. Cette polarité se trouve au cœur des débats qui suivront la parution, en 1968, de l'encyclique Humanae Vitae, laquelle condamnait formellement les méthodes de contraception artificielle. 


\section{D'UN CATHOLICISME À L'AUTRE : TROIS ORDRES CATHOLIQUES AU QUÉBEC ET LEURS REVUES FACE À L'AGGIORNAMENTO, 1962-1970 ${ }^{1}$}

Janine Thériault

Montréal

\section{Résumé}

Le texte qui suit examine le processus de passage d'une forme de catholicisme, celui de l'après-concile de Trente, à celui qui se pratique au Québec depuis le concile Vatican II. Il s'agit principalement d'évaluer le degré d'adaptation de l'Église catholique québécoise à la modernité contemporaine et, en l'occurrence, trois revues en seront les témoins : Relations, publiée par les Pères jésuites, Culture, par les Pères franciscains et Maintenant, par les Pères dominicains. L'étude porte principalement sur les années 1962 à 1970, ce qui est d'autant plus intéressant qu'une polarité idéologique opposait alors la pensée des Jésuites à celle des Dominicains. Cette polarité se trouve au cœur des débats qui suivront la parution, en 1968, de l'encyclique Humana Vita, laquelle condamnait formellement les méthodes de contraception artificielle.

\section{Abstract}

This article examines the adjustment of Quebec's Roman Catholic Church to the reforms brought about by the Second Vatican Council and, in a wider sense, to modernity. Three religious periodicals were selected as the base for this study: 
Relations, the organ of Quebec's Jesuits, Culture, a Franciscan publication, and Maintenant, which was published by the Dominicans. During the 1960s, the province's Jesuits and Dominicans held divergent positions on a number of issues, and these ideological divergences would profoundly affect the debate that followed the publication of Humanæ Vitæ, the 1968 encyclical that condemned artificial means of contraception.

Nul ne peut nier l'ascendant qu'eut l'Église catholique sur plusieurs générations de Québécois. L'importance de la presse religieuse est proportionnelle à cet ascendant et certaines publications ont, plus que d'autres, accompagné les catholiques québécois dans leur marche vers la modernité. C'est pourquoi j'ai choisi de chercher dans le contenu de trois revues, publiées par trois congrégations religieuses catholiques, à démontrer le passage d'un catholicisme à l'autre, autrement dit une adaptation de l'Église catholique québécoise à la modernité contemporaine. Ces revues sont Culture, publiée par les Franciscains, Relations par les Jésuites, et Maintenant par les Dominicains. La première est une revue savante, la seconde un magazine branché sur l'actualité religieuse, sociale, artistique et intellectuelle, la troisième une revue d'opinion centrée sur le dialogue entre clercs et laïcs. L'étude couvre surtout la période 1962-1970, laquelle coïncide avec la Révolution tranquille et le Second Concile du Vatican. Et ce que reflètent ces revues est la pensée de ceux qui la font et pas nécessairement celle de tous les membres des ordres concernés.

Il s'agit d'examiner le processus de passage d'une forme de catholicisme, celui de l'après-Concile de Trente, à celui qui se pratique aujourd'hui, de constater à quel point les revues étudiées reflètent l'accueil des ordres qui les soutiennent aux changements proposés par Vatican II, de voir comment elles illustrent la lutte de pouvoir qui semble alors se 
jouer entre l'Église enseignante, qui est celle de la hiérarchie et des clercs, et l'Église enseignée. De nouvelles théologies nées dans l'Europe du $\mathrm{XX}^{\mathrm{c}}$ siècle ont frayé la voie à Vatican II. L'éthique personnaliste que des philosophes laïcs, tels Jacques Maritain, Emmanuel Mounier, Étienne Gilson et autres ont contribué à promouvoir, en est une des influences et les intellectuels québécois, laïcs autant que clercs, n’y ont pas échappé. Il faut donc se demander dans quelle mesure ces théologies auront aidé l'Église québécoise à évoluer et comment, dans ce contexte, les revues réussissent à traduire le désarroi de certains clercs devant la sécularisation rapide de la société québécoise autant que l'ouverture des autres à ce monde nouveau.

Il est une hypothèse dont il faut bien tenir compte, qui est celle d'une polarité idéologique opposant la pensée des Jésuites à celle des Dominicains, polarité qui d'ailleurs disparaitra graduellement. La crise de la non-confessionnalité des coopératives, qui éclata en 1945 à la suite de la publication d'un manifeste du dominicain Georges-Henri Lévesque, doyen de la Faculté des sciences sociales de l'Université Laval, constitue un bon exemple de cette polarité. L'article, publié dans la revue Ensemble, exprimait l'opinion que la coopérative pouvait et devait être non-confessionnelle. Les Jésuites de l'École sociale populaire firent part de leur désapprobation aux évêques du Québec et au délégué apostolique, $\mathrm{M}^{\mathrm{gr}}$ Antoniutti, qui condamna l'erreur doctrinale présumément commise dans le manifeste ${ }^{2}$. Cette polarité marquera de nouveau le débat sur la régulation des naissances dont l'apogée se situe en 1968, au moment de la parution de l'encyclique de Paul VI, Humana $\checkmark$ ita ${ }^{3}$. Puisqu'il est question de déceler, dans le contenu des revues, le degré de capacité de l'Église québécoise à s'adapter à la modernité contemporaine, dont deux des principales composantes sont la subjectivité et le principe d'autonomie, 
une définition aussi précise que possible de la modernité s'impose a priori.

\section{Définir la modernité}

Dans sa dimension socio-économique, la modernité contemporaine peut être synonyme d'État-providence et de progrès matériel, de social-démocratie, voire d'américanisme. C'est un concept tout à fait occidental et à ce stade, explique l'historien Pierre Trépanier, elle prend le visage « de la politique, plus précisément de la démocratie libérale ${ }^{4} »$. La notion de laïcité y est d'autant plus implicite que la modernité consacre « le divorce du spirituel et du temporel dans la vie collective, et le cantonnement de la religion dans la vie privée ${ }^{5} »$. Pour le sociologue Alain Touraine, la modernité «a remplacé l'unité d'un monde créé par la volonté divine, la Raison ou l'Histoire, par la dualité de la rationalisation et de la subjectivation $^{6}$ ", lesquelles sont "deux figures tournées l'une vers l'autre et dont le dialogue constitue la modernité ${ }^{»}$. En résumé, «il n'y a de modernité que par l'interaction croissante du sujet et de la raison, de la conscience et de la science $^{8} »$. Cela implique le principe d'autonomie en tant que partie constitutive de la modernité au même titre que la subjectivité. Ainsi que l'exprime Alain Renaut, "l'homme de l'humanisme moderne est celui qui n'entend plus recevoir ses normes et ses lois ni de la nature des choses, ni de Dieu mais qui prétend les choisir et les fonder lui-même à partir de sa raison et de sa volonté ${ }^{9}$ ". Cela rejoint tout à fait les explications d'Alain Touraine et de Pierre Trépanier. L'homme moderne, dès lors, n'acceptera plus passivement le discours religieux mais fondera sa foi sur la réflexion et le dialogue avec d'autres croyants, procédé œcuménique qui implique le doute en tant qu'étape de l'itinéraire religieux personnel. L'on peut également se référer à Maurice Blondel dont l'œuvre, qui tend 
à concilier la raison et la foi, l'immanence et la transcendance, " se trouve condensée dans la mise à nu de cet événement qu'il appelle l'alternative ${ }^{10} »$, ce qui contraint au choix et par le fait même à l'abandon du dogmatisme rigide. Cette modernité religieuse complique les rapports entre l'Église enseignante et l'Église enseignée, d'autant plus que le magistère se cramponne à l'orthodoxie. Or, l'Église enseignée cherche à secouer sa traditionnelle passivité et à ajouter l'horizontalité à sa relation verticale avec l'Église enseignante. C'est un équilibre d'autant plus difficile à atteindre qu'il signifie, pour les croyants, liberté et égalité alors que l'Église enseignante cherche pour sa part à concilier foi, responsabilité, tradition, discipline. Les heurts sont dès lors inévitables et pour le croyant, la conciliation de l'autonomie et de l'hétéronomie exige qu'il adhère à l'Église en tant que communauté de foi tout en se prêtant au dialogue. Toutes ces définitions sont compatibles et réfèrent directement au concept de sécularisation, qui est un processus de séparation, de rupture et d'émancipation par rapport à la foi ${ }^{11}$ (chrétienne en l'occurrence), et identifient pour ainsi dire le contexte dans lequel évolue l'Église québécoise depuis la Révolution tranquille.

Les revues analysées sont-elles donc l'expression d'une modernité reposant sur le subjectivisme et dont les mots-clés pourraient être dialogue, option, changement, refus de l'unanimité permanente et du monolithisme ? Il est certain, en tout cas, que la subjectivité et le principe d'autonomie imprégneront le débat entourant la contraception, débat qui s'insère étroitement dans le processus d'Aggiornamento dont un des objectifs concerne la révision de la théologie du mariage et cela, particulièrement après la parution de l'encyclique Humana $V$ ita, que nombre de catholiques percevront comme une entrave à la mise à jour de l'Église. 
Le débat sur la contraception a cela de profondément moderne qu'il est la manifestation d'une volonté, de la part des membres de l'Église enseignée, d'assumer leurs responsabilités en se référant à leur conscience personnelle plutôt qu'à l'obéissance aveugle au magistère. C'est un débat qui se réclame du principe d'autonomie. Quoi de plus représentatif de la modernité, en effet, que les enjeux de la révolution sexuelle en cours : autonomie morale, individualisme, débat démocratique, féminisme. Il s'agit là de la modernité intime à laquelle s'applique très bien la définition d'André Vachon:

Mais la modernité est essentiellement le règne de l'individu, de la conscience, de la liberté ; les hommes n'y accèdent pas autrement qu'un par un, et encore, à certains moments privilégiés, toujours très courts de leur existence. Une nation comme la nôtre est moderne, dans la mesure où elle est faite de consciences individuelles; et elle trouve, elle invente son identité, dans la mesure où ces consciences, une à une, reconnaissent d'autres consciences qui jalonnent le cours d'une histoire $^{12}$.

Le choix de ce thème dont la modernité est l'inspiration dominante, pose donc, en définitive, la question du passage d'un catholicisme à un autre en ce qui a trait à l'autonomie de la conscience du chrétien face au magistère et à son autorité, et à l'adaptation de l'Église catholique au changement par le truchement de l'interrogation et du dialogue.

La modernité est donc liée au changement, lequel repose sur le questionnement, ce qui est logique puisque le changement peut autant découler d'un processus d'interrogation que l'interrogation être suscitée par le changement. Le dilemme auquel les clercs qui publient ces revues sont confrontés se définit donc comme une lutte entre cette modernité menaçante pour l'Église mais à laquelle ils peuvent difficilement 
échapper et le désir de préserver, par le maintien de la tradition, l'influence de cette Église sur la société québécoise. Il illustre la confrontation perpétuelle entre la transcendance et l'immanence. Une définition décisive de la modernité, qui s'applique admirablement à la trame des revues étudiées et permet de comprendre le désarroi qui a pu s'emparer de certains des acteurs de l'époque dont il est question, se trouve dans un ouvrage de Léon Dion:

[...] le changement est le propre de la modernité. Il s'agit d'un changement perpétuel qui bouscule sans répit, avec une rapidité souvent foudroyante, structures, institutions et mentalités. La modernité, c'est le changement imprévisible, insensible aux bouleversements qu'il produit. Ces bouleversements sont ambivalents : sous certains aspects, ils favorisent les personnes et les sociétés; sous d'autres aspects, ils sont susceptibles de produire des dysfonctionnements, des «effets pervers ». La modernisation cause un déséquilibre, elle est source d'inquiétude même chez les personnes qu'elle favorise, et d'angoisse chez celles qu'elle désavantage ${ }^{13}$.

Il s'agit donc d'identifier, à la lecture des trois revues sélectionnées, les effets des changements amenés par le Second Concile du Vatican, ainsi que la volonté d'interrogation et de dialogue présente d'emblée dans la revue Maintenant et qui s'affirmera graduellement ailleurs.

\section{Le personnalisme}

L'influence de l'éthique personnaliste sur la pensée des intellectuels québécois de l'après-guerre est indéniable. L'inspiration des Fernand Dumont, Gérard Pelletier, Pierre Vadeboncœur, Jacques Grand'Maison procéderait, selon E.Martin Meunier et Jean-Philippe Warren, de l'esprit des Emmanuel Mounier, Jacques Maritain, Charles Péguy et autres, 
lequel alimente également les nouvelles théologies qui orienteront Vatican II. La thèse de Meunier et Warren se formule en ces termes :

L'éthique personnaliste contribua à la Révolution tranquille dans la mesure où, dans un premier temps, elle diffusa des normes garantissant, au sein de la catholicité, les éléments d'une critique de la légitimité du régime cléricaliste; et où, dans un second temps, elle contribua à l'ébauche de finalités sociales orientant (du moins à l'origine), le sens des réformes institutionnelles des années $1960^{14}$.

Les nouvelles théologies, qui émergent surtout à partir des années 1930, font partie de ce que Gérard Cholvy et YvesMarie Hilaire appellent «l'âge d'or de la pensée et des lettres chrétiennes ${ }^{15} \%$. L'originalité de l'éthique personnaliste dont ces théologies sont imprégnées réside en ce qu'elle intègre l'histoire à l'étude exégétique : «Dieu parle par l'histoire; l'Église s'alimente de l'histoire; la vérité s'inscrit dans l'histoire; autant de raisons pour les chrétiens d'être à l'écoute des signes des temps ${ }^{16} »$. Le groupe Esprit, par exemple, ouvert tout autant aux protestants, aux juifs et aux incroyants qu'aux catholiques, s'interroge sur la crise de civilisation engendrée par le capitalisme. La théologie du jésuite Henri de Lubac " insiste sur l'enracinement du christianisme dans le judaïsme ${ }^{17}$ » et son influence s'exercera sur le contenu des constitutions conciliaires. Le progrès de l'œcuménisme et le renouvellement de l'ecclésiologie doivent beaucoup aux travaux du dominicain Yves Congar. Déjà, en 1953, il avait conçu un ouvrage intitulé Jalons pour une théologie du laïcat et c'est en partie grâce à lui que Vatican II «souligna la place des laïcs au sein d'une Église formant un peuple, le Peuple de Dieu, où chacun a une place active à tenir ${ }^{18}$ ». Les études bibliques prennent leur essor grâce à la publication de nombreux ouvrages destinés surtout aux séminaristes et qui insèrent les Écritures 
dans le contexte de l'histoire. Les chrétiens démocrates bénéficient du rayonnement d'une abondante presse militante, dont la revue Sept, dirigée par les Dominicains aux éditions du Cerf et qui avait des lecteurs au Québec, n'est qu'un exemple. Cet hebdomadaire disparu en 1937 est de ceux qui, lancés par des ordres religieux comme les Jésuites et les Dominicains, « tranchent nettement sur le conformisme de la droite conservatrice $^{19}$ ». La théologie se renouvelle donc grâce aux études patristiques, bibliques, ecclésiologiques et liturgiques. L'apport de philosophes laïques à cette évolution constitue une originalité et les travaux des Maurice Blondel, Étienne Gilson, Jacques et Raïssa Maritain, Henri-Irénée Marrou, Jean Guitton et autres contribuent à l'enrichissement de la pensée chrétienne moderne.

Le rôle de Jacques Maritain est à signaler plus que tout autre parce qu'il aura une influence sur la pensée des intellectuels québécois, clercs autant que laïcs ${ }^{20}$. Dans son percutant L'bumanisme intégral, publié en 1936, Maritain propose, en résumé, une nouvelle chrétienté qui soit « une civilisation d'inspiration chrétienne fondée sur la liberté, le pluralisme, la tolérance, le respect de la personne » et qui " reconnait une consistance propre au temporel dont les finalités et les caractères sont distincts du monde spirituel ${ }^{21}$ ». Selon Yves Cloutier, le philosophe français aura marqué deux générations d'intellectuels québécois, incluant la plupart des Dominicains, et esquissé « la mission propre du laïcat et de l'activité profane chrétienne à l'égard du monde et de la culture ${ }^{22} »$. Tant Emmanuel Mounier, fondateur de la revue Esprit, que Jacques Maritain ont, «tout en professant un catholicisme rigoureux et respectueux des dogmes, [...] élaboré une pensée politique, économique et sociale dont les grands axes sont la démocratie, la valorisation de la liberté personnelle et des droits individuels, la laïcité, la justice sociale et l'interventionnisme 
étatique ${ }^{23}$ ». C'est donc la France qui servira de modèle aux intellectuels catholiques québécois ainsi qu'à de nombreux clercs ayant étudié dans ses universités. L'Université catholique de Louvain, en Belgique, fut également un lieu d'étude pour nombre d'entre eux.

Le pontificat de Pie XII, par ailleurs, sera pétri de conservatisme et d'autoritarisme. La revue Relations louera son anticommunisme et son opposition à ces nouvelles théologies dérivant d'une déplorable "manie de nouveauté et [de] propos mal réglé d'apostolat ${ }^{24} »$.

\section{L’Église québécoise et le concile Vatican II}

Les revues dont il est question dans cette étude décrivent admirablement l'état des lieux à l'époque étudiée. De 1958 à 1965, confrontée à la Révolution tranquille et entrânée par le concile Vatican II voulu par le pape Jean XXIII, l'Église du Québec repense son apostolat, réinvente une pastorale d'ensemble, restructure l'action catholique, baigne dans l'œcuménisme. Pie XII, dernier pape de l'ère tridentine, s'éteint à l'automne 1958 et son successeur, Jean XXIII, entraînera l'Église dans une mise à jour sans précédent. De ce concile surgiront quatre constitutions, neuf décrets, trois déclarations et quantité de malentendus. Autrement dit, le contenu du Concile a été mal compris et «l'interprétation de ses décisions et leur application ont donné lieu, au dire de Gérard Cholvy et Yves-Marie Hilaire, à des débats qui ne sont pas $\operatorname{clos}^{25} \%$. André Naud, proche collaborateur de l'archevêque de Montréal, le cardinal Paul-Émile Léger, pendant la préparation et lors du Concile, avouera sa propre perplexité, au sortir de l'événement, devant la précarité de certains acquis lesquels, écrit-il, "avaient été imparfaitement formulés » et que beaucoup contestaient. C'était le cas de la doctrine de la collégialité et de celle des fins du mariage «dont on savait 
qu'elle n'avait pas pleinement pénétré les esprits, avec toutes les conséquences dont elle aurait dû être porteuse ${ }^{26} »$.

Peut-être aussi les attentes des catholiques, du moins ceux de l'Occident septentrional, se situaient-elles hors du champ d'étude proprement dit de Vatican II, Jean XXIII ayant fait du rapprochement avec les frères séparés l'objectif suprême de l'événement. Or ces catholiques semblent avoir espéré, contre toute attente, une attitude de tolérance, sinon d'acceptation, des mentalités et pratiques entourant la libération sexuelle en cours, ce qui serait revenu, pour l'Église, à se détourner de sa propre morale tout en sapant les fondements de sa théologie. Cela aurait aussi dépassé de loin les attentes exprimées dans les articles publiés en 1962 dans Relations et dans Maintenant, ainsi que celui de Cantius Matura, O.F.M., paru en 1960 dans Culture. Ce dernier s'intitule «Le renouveau biblique contemporain et sa signification ${ }^{27}$ » et l'auteur y explique les aspects scientifique et spirituel du renouveau biblique ainsi que les avantages de leur conjonction pour un retour fructueux aux sources de l'Écriture et pour une mise à jour de la vie intérieure de l'Église. Cela mènerait à établir un dialogue entre la Parole et l'homme en mettant l'Écriture à la disposition de tous les chrétiens. La pensée que traduit ce texte apparait comme une amorce d'abolition du clivage entre l'Église enseignante et l'Église enseignée parce qu'il constitue une invitation à rehausser le niveau de connaissance du laïcat. Ce texte s'inscrit donc dans la foulée des nouvelles théologies évoquées ci-haut, qui servirent d'inspiration aux pères conciliaires. Pour sa part Jean Lacroix, professeur à Lyon, invité à prendre la parole lors de la Semaine sociale d'août 1962, souhaite avant tout l'élaboration d'une spiritualité pour les laïcs, lesquels font, par la grâce du baptême, partie du peuple de Dieu. Dans le texte qu'il propose à Relations, Jean Lacroix insiste avant tout pour que cette spiritualité concerne 
l'action temporelle, politique surtout, et espère une décléricalisation des mouvements laïques parce que c'est à eux et non aux aumôniers à les diriger. Il souhaite que par le dialogue, mot qui somme toute signifie « rénover pour susciter l'unité ${ }^{28}$ ", les laïcs en viennent à posséder une doctrine chrétienne susceptible d'être pleinement vécue. Quant au prêtre Jean Martucci qui, dans un article de Maintenant, emploie la même définition du dialogue que Jean Lacroix, définition empruntée à un ouvrage de Hans Küng, il s'exprime au nom de tous les catholiques et souhaite une fidélité adaptée et enrichie à la Tradition. Dans le cadre d'un forum dont certains exposés sont reproduits dans la revue, il réclame de l'Aggiornamento qu'il soit précédé d'une «critique judicieuse, libératrice, fructueuse et constructive ${ }^{29} \gg$. Ces attentes correspondent aux objectifs du Concile : dialogue entre chrétiens, diversité dans l'unité, réponse aux angoisses du monde contemporain, stimulation de l'apostolat laïque, liturgie adaptée, respect et acceptation des rites orientaux, intégration des valeurs humaines propres aux différentes cultures, structures juridiques décentralisées, etc. ${ }^{30}$ Dans le même numéro, le pasteur Daniel Pourchot, pour sa part, émet l'espoir que le Concile «se penche longuement sur la question du ministère des laïcs ${ }^{31} »$. Les revues se montrent optimistes mais rien ne laisse encore prévoir la crise profonde qui s'en vient et dont la libération sexuelle sera l'un des enjeux les plus spectaculaires.

Le cardinal Paul-Émile Léger laissera sa marque parmi les pères conciliaires. De prime abord réticent, il finira par s'engager à fond dans la préparation et le déroulement de l'événement. Ainsi participera-t-il à la Commission préparatoire au Concile et se rangera-t-il aux avis de l'aile progressiste $\mathrm{du}$ laïcat catholique : «dialogue, attention à la personne, attitude plus positive à l'égard du monde, de l'évolution sociale et du laïcat ${ }^{32} . »$ La pertinence de ses interventions sera remarquée 
pendant les quatre sessions de Vatican II ; l'une d'elles, entre autres, qui concerne la théologie du mariage, fera la une des journaux. Opposé à la condamnation des méthodes de contraception naturelles, telles la méthode Ogino et la méthode sympto-thermique, le cardinal affirmera que "l'union intime des époux trouve aussi dans l'amour une fin $^{33} »$. De retour chez lui, il n'hésitera pas non plus, fidèle en cela aux motsclés du Concile que sont adaptation et dialogue, à tirer parti de la laicisation progressive de la société et à promouvoir l'engagement du laïcat dans les affaires de l'Église. C'est avec résolution que, de retour dans son diocèse, il s'attellera à la mise en application des décisions du Concile par l'élaboration d'un nouveau projet ecclésial et social. Ainsi mettra-t-il en œuvre la réforme liturgique proposée par le Concile.

Mais l'Aggiornamento ne comblera qu'une partie du retard de l'Église catholique sur le monde moderne et celle du Québec est à ce moment aux prises avec ce que le sociologue Guy Rocher appelle "l'idéologie du changement comme facteur de mutation sociale ${ }^{34} "$, idéologie qui est en même temps porteuse de modernité. Un conflit s'amorce pour le Québécois moderne, qui doit composer non seulement avec le changement perçu comme la solution à tous les problèmes, mais avec l'indifférence religieuse qui le gagne, voire avec l'incroyance. Plus que d'incroyance proprement dite, il s'agit de déchristianisation de la croyance avec, entre autres conséquences, l'adhésion à une multitude de sectes et de mouvements de spiritualité. Pourtant, malgré la désaffection religieuse qui marque la Révolution tranquille, la majorité des Québécois a tenu à conserver son identité catholique. Et si l'Église s'est tant bien que mal résignée à la sécularisation de la société québécoise, c'est sans doute que plusieurs clercs, conscients des impératifs de la modernité, l'avaient souhaitée et avaient soutenu les réformes entreprises par la Révolution tranquille 
tout en accueillant avec enthousiasme l'Aggiornamento proposé aux catholiques par le pape Jean XXIII. Ce clergé progressiste encourageait l'ajustement de l'Église à la modernité et à ses conséquences sur la société québécoise : néonationalisme, sécularisation, espoir d'une société plus juste. Sans doute n'avait-il pas prévu qu'en se libérant des aspects étouffants du catholicisme le peuple canadien-français, les jeunes surtout, déserterait les églises. Il ne pouvait non plus pressentir le syncrétisme religieux auquel la société québécoise allait bientôt adhérer ${ }^{35}$, se réinventant par le fait même des religions faites sur mesure.

Le Québec se trouve donc secoué par une crise religieuse consécutive aux remises en question suscitées tant par Vatican II que par la modernité. Ces questions concernent, par exemple, les méthodes de contraception et les changements dans la liturgie, mal acceptés par les parties conservatrices. Le Concile, en effet, n'a rien d'un achèvement malgré le travail colossal effectué durant ses quatre sessions. Il faudra en effet l'expliquer et mettre en œuvre les réformes préconisées. Mais en cette époque de contestation des valeurs véhiculées par la civilisation occidentale, les attentes sont grandes.

Les revues suivront donc, chacune à sa manière, les travaux du Concile et s'intéresseront à ses suites. Il y sera question de réforme liturgique, de morale du mariage, de collégialité dans le gouvernement de l'Église, de rapprochement avec les frères séparés, d'engagement du laïcat. Entre autres documents, quatre constitutions résulteront des quatre sessions de Vatican II : Dei verbum, constitution dogmatique sur les sources de la Révélation; Lumen gentium, constitution dogmatique sur l'Église ; Sacrosanctum concilium, constitution pastorale sur la liturgie; Gaudium et Spes, constitution pastorale sur l'Église dans le monde de ce temps. Des trois 
revues, Relations est celle qui décrira, analysera et commentera les phases de l'événement avec le plus d'assiduité et le plus de rigueur théologique. Maintenant, revue d'opinion avant tout, réfléchira beaucoup sur les conséquences de l'Aggiornamento, sur l'impact actuel et éventuel des actions de la Hiérarchie. Culture se montre plus laconique tout en offrant quelques articles remarquables sur des questions relatives à l' $A g$ giornamento. Autrement dit, Relations constitue une excellente source d'information événementielle et analytique alors que les autres périodiques scrutent le sujet de façon plus générale pour ce qui est de Culture et plus critique pour ce qui est de Maintenant.

\section{Relations}

Fondée en 1941 en remplacement de L'Ordre nouveau, qui était l'organe de l'École sociale populaire et des Semaines sociales des Jésuites, Relations se mue, vers 1950, en publication d'intérêt général. À l'époque décrite ici, son directeur est Richard Arès, S.J., qui sera remplacé en 1969 par Irénée Desrochers, S.J., mais demeurera membre de l'équipe de rédaction. Ceux qui font Relations ont une réputation de conservatisme. Il importe cependant de savoir que la seule politique à laquelle les Jésuites soient acquis est celle des pontifes absolutistes qui se sont succédé jusqu'à Jean XXIII. Ils participeront activement à l'élaboration et à la transmission de la doctrine sociale de l'Église, militeront contre le communisme et, au Québec, se feront en quelque sorte les "penseurs attitrés du nationalisme traditionaliste ${ }^{36} »$. Ainsi l'évolution et le développement de Relations se déroulent-ils, constate le sociologue Pierre Beausoleil, "selon un axe bien défini : le service officiel de l'Église institutionnelle, selon une très grande fidélité à la tradition, au magistère de Rome et aux directives de l'épiscopat canadien ${ }^{37}$ ». Ajoutons que les encycliques cons- 
Tableau I. Revue Relations

\begin{tabular}{|c|c|c|c|c|}
\hline \multicolumn{2}{|l|}{ Année } & 1958 & 1965 & 1970 \\
\hline \multicolumn{2}{|l|}{ Tirage* } & 13868 & 12777 & 9208 \\
\hline \multicolumn{2}{|c|}{ Abonnement } & $4 \$$ & $5 \$$ & $6 \$$ \\
\hline \multicolumn{2}{|c|}{ Exemplaire } & $34 \notin$ & $50 \varnothing$ & $60 \not$ \\
\hline \multirow{7}{*}{ Clientèle } & Professionnels & 5853 & \multirow{7}{*}{$\mathrm{n} / \mathrm{d}$} & \multirow{7}{*}{$\mathrm{n} / \mathrm{d}$} \\
\hline & Gens d'affaires & 1076 & & \\
\hline & Membres du clergé & 1442 & & \\
\hline & Institutions religieuses & 945 & & \\
\hline & Autres & 4480 & & \\
\hline & Invendus & 72 & & \\
\hline & TOTAL & 13868 & & \\
\hline
\end{tabular}

* Les données concernant les tirages sont foumies par les guides CARD (Canadian Advertising Rates and Data) 
tituent pour ainsi dire le manuel de référence des Jésuites et que la sécularisation en cours, perçue par Richard Arès comme " notre plus visible signe des temps ${ }^{38}$ ", préoccupe grandement les rédacteurs de la revue. Cela définit bien la substance, le caractère de cette publication conservatrice mais sensible aux changements en cours lorsqu'ils sont approuvés par le magistère et qui fera bon accueil au programme proposé par le Concile.

\section{Culture}

Cette magnifique revue bilingue, fondée en 1940 par Edmond Gaudron, O.F.M., avait comme objectif d'initier les deux peuples fondateurs du Canada à la connaissance de leur culture respective et de les inciter à reconnaître leur complémentarité. Le père Gaudron, qui anima la revue depuis sa fondation jusqu'à la parution du dernier numéro, en décembre 1970, pensait «que l'avenir est aux peuples qui entretiennent en eux une mentalité mondiale pluraliste et accueillante, pour qui le voisin n'est pas un ennemi, mais un humain aux prises avec des passions de tous ordres, capable cependant de sincérité et d'audience ${ }^{39}$ ». Alors que Relations et Maintenant sont publiées mensuellement et couvrent la plupart des aspects de l'actualité, Culture est trimestrielle et se présente comme publication scientifique. Elle ne suit pas les travaux du Concile avec la même assiduité que les autres publications mais il est possible, à travers des textes théologiques, sociologiques ou historiques, d'y repérer une conscience tout à fait lucide des défis désormais lancés à l'Église par la modernité.

\section{Maintenant}

Au mois de janvier 1962 est lancé le mensuel Maintenant, en remplacement de La Revue dominicaine qui, depuis 1915, s'était faite organe de diffusion du thomisme. Fondé 
par le père Henri Bradet, le nouveau périodique se veut plus engagé et ouvert à des valeurs axées sur la liberté d'opinion et d'expression, sur la connaissance et le respect de la personne, sur une liberté qui soit synonyme de maturité et de responsabilité. On le voudra publication d'avant-garde apte à démontrer la compatibilité du catholicisme et de la modernité au moyen du dialogue, les catholiques évoluant désormais dans un contexte de laïcisation institutionnelle, de progrès matériel et d'État-providence propre à susciter des interrogations. Car le dialogue est un aspect de la modernité, il est fils de l'interrogation.

La grandeur de la pensée moderne, de la culture moderne, de la civilisation moderne c'est la dose d'interrogation qu'elle porte en elle, qui dit interrogation dit question sans réponse suffisante, dit entrée progressive dans les réponses, dit donc désaccord entre les réponses des uns et les questions que se posent encore les autres $^{40}$.

Plusieurs laïcs, hommes et femmes, seront invités à y collaborer. Cela distingue d'entrée de jeu Maintenant de Relations qui, par son analyse approfondie des encycliques et des constitutions est sans contredit plus rigoureuse sur les plans théologique et scientifique alors que Maintenant s'ouvre davantage à ce troupeau qui, somme toute, est la raison d'exister du pasteur. En 1965, le père Bradet sera congédié à la suite d'une série d'articles concernant la limitation des naissances, jugés, autant que le contenu général de la revue, trop audacieux par les supérieurs de l'ordre. Il sera remplacé, en janvier 1966, par le père Vincent Harvey.

\section{Trois revues face à l'Aggiornamento}

La revue Relations publie régulièrement des numéros spéciaux consacrés à des événements aussi exceptionnels que 
Tableau II. Revue Culture *

\begin{tabular}{|l|c|c|c|}
\hline Année & $\mathbf{1 9 5 8}$ & $\mathbf{1 9 6 5}$ & $\mathbf{1 9 7 0}$ \\
\hline Tirage & 1000 & 800 & 800 \\
\hline Abonnement & $3 \$$ & $3 \$$ & $3 \$$ \\
\hline Exemplaire & $1 \$$ & $1 \$$ & $1 \$$ \\
\hline
\end{tabular}

* Archives de Culture

Tableau III. Revue Maintenant*

\begin{tabular}{|l|c|c|c|c|}
\hline Année & $\mathbf{1 9 6 2}$ & $\mathbf{1 9 6 6}$ & $\mathbf{1 9 6 8}$ & 1974 \\
\hline Tirage & $\mathrm{n} / \mathrm{d}$ & 20000 & $\mathrm{n} / \mathrm{d}$ & 4000 \\
\hline Abonnement & $5 \$$ & $5 \$$ & $7 \$$ & 9 \\
\hline Exemplaire & $50 \not$ & $50 \not$ & $75 \not$ & $1 \$$ \\
\hline
\end{tabular}

* André Beaulieu et al., La presse québécoise des origines à nos jours, tome 9, Québec, PUL, 1989. 
la parution d'une encyclique. Culture s'intéresse également aux encycliques, notamment à Mater et magistra dont Louis-Nazaire Hamel, O.F.M., fait la synthèse de la troisième partie dans l'article « Mater et magistra. Une conception totalitaire du monde social ». Cette encyclique rend compte de certains des objectifs pratiques de l'Aggiornamento et Jean XXIII la publie en 1961, en continuité avec les encycliques de Léon XIII (Rerum novarum) et de Pie XI (Quadragesimo anno). Cette troisième partie de l'encyclique se veut une explication de la "pensée de l'Église du Christ sur les nouveaux et les plus importants problèmes du moment ${ }^{41} »$. C'est un document en continuité avec les fondements de la doctrine sociale de l'Église, mais dicté par la nouvelle situation scientifique, technique et économique. Il relève, comme les encycliques précédentes, des « exigences de la justice et de l'équitét ${ }^{42} »$. Ce document constitue une étape majeure de l'évolution de la doctrine sociale de l'Église.

En octobre 1962, Relations propose à son lectorat un numéro spécial consacré au Concile et, en février 1966, un autre sur l'après-Concile, dont on est loin de pressentir les suites qui seront examinées avec autant d'intérêt que l'événement lui-même. Une fois le Concile amorcé, même les Jésuites les plus réticents à l'égard des théologies d'avant-garde, tel Luigi d'Apollonia, S.J., accueillent favorablement les changements proposés tout en prêchant la prudence dans l'innovation et le respect des institutions et des valeurs fondamentales de l'Église. Ils mettront le public en garde contre une tendance à politiser l'Église, c'est-à-dire à la vouloir au service de l'homme et à ne s'intéresser au Concile qu'en fonction des problèmes et du perfectionnement de la personne humaine ${ }^{43}$. L'attention de la revue sera plutôt accordée aux attentes de nature spirituelle mais qui tiennent compte de la sécularisation inhérente à la modernité contemporaine : les 
laïcs attendent du Concile qu'il fasse la lumière sur le seul problème essentiel qui est «l'incarnation du message évangélique dans le monde moderne en fonction d'une humanité de plus en plus responsable et maitresse de son destin ${ }^{44}$ ».

Par ailleurs, si beaucoup de laïcs collaborent à Maintenant et à Culture, en revanche Relations ne leur donne que rarement la parole, à plus forte raison lorsqu'il est question de l'Église. Ces Jésuites font preuve d'un réformisme tempéré par la vision traditionnelle du rapport de supériorité du sacré sur le profane et du clergé sur le laïcat.

Une différence de perception fondamentale est à signaler pour qui cherche à comparer Relations et Maintenant. Gaëtan Baillargeon l'identifie avec justesse lorsque, dans un chapitre du collectif L'Église canadienne et Vatican II il souligne que Luigi d'Apollonia cherche la raison du Concile dans «la crise du monde contemporain » alors que le dominicain Pierre-André Liégé (qui collabore régulièrement à Maintenant), dans un article de la revue Communauté chrétienne signale une crise à l'intérieur même de l'Église ${ }^{45}$.

Voyons maintenant de quelle façon les revues traitent de certains des sujets débattus au Concile, lesquels se matérialisent en 69 schémas formant 121 fascicules qui totalisent 2100 pages, que dix Commissions spécialisées sont chargées d'étudier. En ce qui concerne les rapports entre l'Église et l'État, par exemple, Richard Arès voit s'ouvrir une perspective nouvelle qu'il qualifie de personnaliste. Il réclame de l'Église qu'elle fasse sien le principe de liberté religieuse, qui est également celui de sa propre liberté. Il demande aussi au Concile de proclamer «les droits primordiaux et les libertés fondamentales, tant de la personne humaine en général que des groupements religieux en particulier ${ }^{46} »$. C'est là une vision progressiste en accord avec la déclaration sur la liberté de religion, objet de houleux débats au Concile, et qui ne verra 
le jour qu'à l'issue de l'événement. Maintenant va plus loin et discute abondamment de la liberté religieuse, intimement liée à la question œcuménique puisqu'il ne saurait y avoir de véritable ocuménisme sans reconnaissance de la personne, par conséquent sans acceptation de la liberté de religion, voire de non-religion et sans ouverture à la vraie laïcité, laquelle «se découvre à la suite d'un épanouissement de la conscience de la liberté en chaque être ${ }^{47}$ \%. Cela implique un changement de mentalité du clergé à l'égard des laïcs par l'adoption du schéma reconnaissant la place et le rôle de ces derniers au sein de l'Église ${ }^{48}$.

Pas de dialogue non plus, pas d'engagement efficace du laïcat, pas d'Aggiornamento sans assouplissement de la tension autorité-libertét ${ }^{49}$ et sans reconnaissance officielle des protestants et des orthodoxes. Ce pas est heureusement franchi par l'admission, dans l'enceinte des travaux conciliaires, d'observateurs non-catholiques qui ont accès aux mêmes documents que les Pères et peuvent ainsi informer leurs mandataires des décisions qui se prennent. Le pasteur Daniel Pourchot se fait le porte-parole, dans le cadre de la revue Maintenant, des frères séparés qui sont, au même titre que les catholiques romains, membres du corps du Christ. Plutôt conservateur, Paul Mailleux, S.J. estime, dans le Relations spécial d'octobre 1962, que la réconciliation entre chrétiens d'Orient et d'Occident est conditionnelle à la reconnaissance par les Orientaux de la mission pastorale confiée à Pierre et qui se perpétue à Rome. Doris Lussier parle de liberté dans un article de Maintenant dénonçant l'intégrisme religieux qui, en imposant par la peur ou la contrainte l'acte de foi, le transforme aux yeux de Dieu « en grimace de l'esprit ${ }^{50}$ ». La Direction de Maintenant, en attente de la déclaration sur la liberté religieuse, réitère cette dénonciation de l'intolérance en affirmant que « la contrainte, lorsqu'elle s'exerce au nom de Dieu, ne forme que des 
athées ${ }^{51} »$. Liberté et respect de la conscience étant idées modernes, le Concile proclamera la liberté religieuse comme " un droit inaliénable de l'homme... [elle est] requise par la juste compréhension de l'Évangile ${ }^{52} \%$. Autre concession, et de taille, à la modernité, la déclaration sur la liberté religieuse constitue également une reconnaissance implicite de l'État laïque, condition nécessaire à l'application concrète de cette liberté. Autant le dominicain Christian Duquoc que le laïc Michel Despland sont d'accord là-dessus, chacun ayant insisté dans son article respectif sur le fait que la déclaration sur la liberté religieuse ne trouve un sens que dans un contexte d'État (sainement, d'appuyer Duquoc) laïque ${ }^{53}$. Et, d'ajouter Jean-Paul Vanasse, la liberté est un risque puisque l'interrogation (et le désaccord aurait ajouté V. Cosmao) en fait partie. Mais elle demeure le plus sûr moyen d'affronter la tempête dont Emmanuel Mounier, cité par J.-P. Vanasse, avait perçu les signes dans l'amère évidence que la religion était en voie de devenir " une habitude sans signification profond $\mathrm{e}^{54}$ ».

La première session se termine sans qu'aucune ligne définitive ne se dégage et l'événement promet de durer plus longtemps que prévu. Jean XXIII expire le 3 juin 1963 et c'est à son successeur, Paul VI, que revient la décision de convoquer une deuxième session, laquelle se tient à l'automne suivant. C'est de cette session que sortira le premier texte officiel de Vatican II, promulgué par le nouveau pontife le 4 décembre 1963. Il s'agit de la constitution Sacrosanctum concilium sur la Liturgie, laquelle promeut une réforme liturgique qui sans doute sera la plus concrète des manifestations de l' $A g$ giornamento ou du moins la plus visible aux yeux du laïcat. L'éditorialiste de Relations la verra comme une étape importante de la « rénovation spirituelle ${ }^{55}$ » entreprise parce que les éléments liturgiques créés par l'Église dans le but d'accompagner les éléments fondamentaux venus du Christ, qui sont 
essentiellement le sacrifice et les sacrements, avaient besoin d'être simplifiés et renouvelés. Le passage d'un catholicisme à l'autre, donc de l'Église de chrétienté à l'Église missionnaire, se manifeste particulièrement dans cette constitution, perçue par l'abbé Jacques Leclercq, prêtre français qui collabore à Maintenant, comme étant la pièce maîtresse du Concile $^{56}$. Il est visible également dans Lumen gentium, qui recommande la présence et l'action du laïcat ainsi que l'exercice d'une autorité centrée sur le dialogue au moyen de la démocratie et de la collégialité ${ }^{57}$. Car cette deuxième session s'ouvre également avec l'étude du schéma sur l'Église, prémisse de la constitution Lumen gentium. Les discussions portent notamment sur la réforme de la Curie romaine et sur la collégialité épiscopale. Selon Luigi d'Apollonia, l'épiscopat constitue la question centrale du Concile car il est urgent de définir son rôle, ses pouvoirs et surtout sa place dans la constitution de l'Église, laquelle est hiérarchique avec un pouvoir suprême formé de deux sujets, le pape, « héritier en personne de l'autorité et la charge conférées à Pierre en personne », et le collège épiscopal qui doit œuvrer en communion avec le pontife et sous son autorité ${ }^{58}$. Il s'agit en somme pour le Concile de déterminer si le collège des évêques succède de droit divin à celui des apôtres et d'établir « la manière dont le pouvoir collégial s'exercera dans l'Église ${ }^{59} »$. Le schéma ne sera cependant pas voté immédiatement et sera au programme de la troisième session, qui voudra surtout s'attarder aux rapports entre la papauté et l'épiscopat. La revue Maintenant traite la question de la collégialité sous un angle différent. Si l'article de Luigi d'Apollonia est surtout explicatif et axé sur la relation entre papauté et épiscopat, celui que signe Gregory Baum pour Maintenant, tout en considérant, autant que son vis-à-vis, la collégialité comme une des questions majeures du Concile, met l'accent sur le dialogue, en voie de devenir la structure 
de «l'exercice de l'autorité suprême [...] à tous les échelons du gouvernement de l'Église » et perçoit le Concile comme étant « l'expression achevée de cette collégialité ${ }^{60} »$. Pour Baum, la collégialité est une conception du gouvernement de l'Église qui la rapproche de "l'idéal recherché au $\mathrm{XX}^{\mathrm{e}}$ siècle par les États, les compagnies ou les universités ${ }^{61} »$, donc l'introduit de plain-pied dans la modernité. Ces façons de traiter d'un même sujet apparaissent comme l'expression d'une conception différente de l'autorité. C'est aussi, en ce qui concerne Maintenant, la démonstration du choix fait par la revue de se consacrer au dialogue et peut-être est-ce également l'application aux revues de deux tendances intellectuelles parmi les Pères conciliaires, dont fait état Luigi d'Apollonia dans un article intitulé « Les trois conciles ». La première juge les projets en fonction de la doctrine, du droit établi et du dépôt à conserver et caractérise Relations, l'autre juge «du point de vue de la pastorale, des exigences nouvelles et du message à répandre ${ }^{62} »$ et correspond à la position de Maintenant. Les deux tendances sont nécessaires, d'ajouter d'Apollonia, car elles sont facteurs d'équilibre. Mais, particulièrement en ce qui concerne les revues, elles restent des tendances et non pas des positions rigides.

Une des préoccupations majeures des rédacteurs de Relations est de dissiper les « idées imaginaires ${ }^{63}$ » que pourrait entretenir le public sur l'Église et la modernité. Il y aura, par exemple, des mises en garde concernant le mariage et la régulation des naissances. Beaucoup de textes illustrent d'ailleurs le tiraillement entre progrès et tradition qui est la caractéristique de Relations à cette époque. Le problème de la conciliation de la modernité et de la mission de l'Église qui est, particulièrement aux yeux des collaborateurs de la revue Maintenant, de spiritualiser le monde et non de le juger, se retrouvera tout entier dans le débat sur les méthodes de contraception 
mais il concerne aussi l'autonomie de la science. À cet égard, le dominicain Paul Doucet se réjouira de la demande de réhabilitation officielle de Galilée faite par $\mathrm{M}^{\mathrm{gr}}$ Elchinger. Le savant italien, dont les recherches étaient publiées dans le climat de sévérité doctrinale hérité du Concile de Trente, accusait effectivement les théologiens de prêcher des doctrines si contraignantes pour l'intelligence qu'elles en suscitaient l'hérésie. Galilée était, selon Paul Doucet, contemporain de Vatican II par « la tension qu'il a eue a subir entre sa fidélité à l'Église et ses convictions scientifiques ${ }^{64} »$.

À l'ouverture de la session de 1964, il reste donc trois discussions complémentaires au schéma sur l'Église menant à la promulgation de la constitution Lumen gentium, trois discussions à entamer concernant la Révélation (constitution $D e i$ verbum), l'apostolat des laïcs et l'Église dans le monde d'aujourd'hui (schéma XIII duquel sortira la constitution Gaudium et Spes). Il y a également sept schémas à voter sans discussion, lesquels concernent les Églises orientales, les missions, les religieux, les prêtres, les séminaires, les écoles catholiques et le mariage. Cette troisième session terminée et la constitution dogmatique sur l'Église, Lumen gentium, promulguée, il restera onze schémas à l'ordre du jour de la quatrième et dernière session prévue pour l'automne 1965, dont ceux qui portent sur la liberté de religion, l'Église dans le monde de notre temps, la Révélation, l'apostolat des laïcs, l'adaptation et le renouvellement de la vie religieuse dont il est aussi question dans Lumen gentium.

Le schéma XIII aura connu une naissance difficile mais des idées générales en émergent qui portent surtout sur le « sens à donner au mot monde et la place à donner au phénomène de l'athéisme contemporain ${ }^{65} \%$. Pendant les mois qui précèdent l'ultime session, les évêques prennent connaissance des schémas préparés par des experts qui par ailleurs n'ont accès 
ni aux délibérations ni au vote. Ce sont les évêques qui constituent le seul vrai Concile, ainsi que l'explique Luigi d'Apollonia ${ }^{66}$, et c'est à "l'unanimité », qu'il explique comme étant une majorité constituée d'au moins les deux tiers des votes, que les résolutions sont adoptées. Dans le cas de discussions sur des sujets aussi délicats que celle qui concerne la déclaration sur les Juifs, que les musulmans pourraient interpréter comme une prise de position politique, les Pères doivent faire preuve de prudence. Le texte définitif, d'ordre essentiellement théologique, rappellera la passion et la mort volontaires de Jésus destinées à parfaire plutôt qu'à abroger l'ancienne alliance et cherchera à dissiper l'impression erronée que le Christ s'opposait aux Juifs alors que lui-même, ses parents et ses disciples faisaient partie de ce peuple ${ }^{67}$.

Le nouveau, c'est l'orientation solennellement donnée en vue de faire comprendre et aimer d'une manière chrétienne tous les non-chrétiens mais, en particulier, les Juifs, très chers à Dieu, et de purifier nos lèvres et nos cœurs de tout antisémitisme, bref, de nous faire un cœur catholique ${ }^{68}$.

Maintenant insiste également sur la révision des rapports entre catholiques et juifs et en cela son point de vue est proche de celui de Relations. Culture n'en parle pas mais certains de ses collaborateurs sont juifs et protestants, ce qui en fait d'emblée une revue œcuménique.

Dans le cas de la déclaration sur la liberté religieuse, comme dans celle sur les non-chrétiens et les Juifs, il y aura inévitablement confrontation des tendances pour aboutir, au rythme d'une dialectique fructueuse, à la «convergence progressive des esprits ${ }^{69}$ ». Ce débat sera le premier à l'ordre du jour de la quatrième session et il sera ouvrage de patience, sagesse, mesure. Luigi d'Apollonia en disserte longuement ${ }^{70}$. Cette Déclaration défendra la cause de la liberté et de la reli- 
gion, en accord avec la Révélation et « au nom de la dignité et de la vocation de la personne humaine ${ }^{71} »$.

Les Jésuites de Relations s'intéressent donc assidûment aux travaux du Concile et accueillent favorablement l'esprit nouveau qui souffle sur la chrétienté parce qu'ils espèrent y trouver réponses aux « angoissantes questions ${ }^{72}$ " que se pose l'Église du Québec. Ils approuvent la volonté de dialogue qui est à la source de l'événement et qui traduit l'ouverture de l'Église catholique à l'œcuménisme, c'est-à-dire à une meilleure compréhension entre chrétiens de différents rites et entre chrétiens et non-chrétiens. Ils saluent avec d'autant plus d'enthousiasme les constitutions, déclarations et décrets qui émanent de Vatican II que l'intégrité de la doctrine fondamentale du christianisme demeure intacte et que, malgré un renouvellement de la doctrine sur les fins du mariage, l'Église reste sur ses positions traditionnelles en matière de contraception, de divorce, de célibat des prêtres, etc. Le renouvellement de la liturgie, le recours à la langue vernaculaire ne sont pas remis en question, les déclarations sur les Juifs et sur la liberté religieuse sont unanimement approuvées, ce qui constitue bel et bien une rupture et l'indice du passage d'un catholicisme à l'autre. Plusieurs des théologiens d'avant-garde qui ont préparé le Concile sont jésuites et les rédacteurs de Relations sont de toute évidence influencés par les nouvelles théologies défendues par leurs confrères européens. Pour ce qui est de l'accueil à l'Aggiornamento il est donc possible de conclure à une tendance progressiste dans le contenu de Relations, dans la mesure où le renouvellement proposé par le Concile est le fruit de l'unanimité conciliaire et de l'approbation pontificale. Les Jésuites québécois se rangent bel et bien du côté des réformistes, c'est-à-dire de ceux qui, au sens où l'entendait Marcel Adam dans un article de la revue Maintenant, "favorisent une mise à jour de l'Église ${ }^{73}$ » alors que les antiréformistes 
n'y croient pas et vont même jusqu'à la juger dangereuse. La revue demeure par contre conservatrice dans sa vision du problème de la régulation des naissances - nous le verrons plus loin - et parce que, contrairement à Maintenant, et même à Culture, où l'apport des laïcs est important, elle ne donne que rarement la parole à ces derniers et uniquement en matière de politique, d'économie ou d'affaires publiques. Les questions théologiques et morales restent l'apanage des clercs et à ce niveau, Relations n'est encore qu'un long soliloque. La différence fondamentale entre les deux revues réside surtout dans l'approche ou la méthode, Maintenant réservant au laïcat une part importante du corpus, Relations privilégiant le clergé. La tendance générale de Relations est surtout doctrinale, c'est-àdire que l'on privilégie encore les projets soumis «en fonction de la doctrine et du droit établis, et du dépôt à conser$\operatorname{ver}^{74} »$. Celle de Maintenant est plus axée sur « la pastorale, les exigences nouvelles et le message à répandr ${ }^{75}$ ». C'est, enfin, l'illustration d'une volonté mutuelle de favoriser le changement par des approches différentes, l'une empruntant à la tradition, l'autre au progressisme.

Pour ce qui est de Culture, les textes parcourus traduisent sa recherche d'une alternative au vide existentiel qui marque cette époque et qui s'amplifiera dans les années suivantes, non sans que la société y cherche des palliatifs. Quoique sans référence directe avec le Concile, ce sont des exposés qui adhèrent manifestement à la réalité vécue tant par la chrétienté que par la société tout entière et qui traduisent les préoccupations engendrées par la modernité et la sécularisation.

Ainsi en est-il de l'article de Gonzalve Poulin, O.F.M., publié en 1965, et qui se veut une réflexion sur l'Église dans un Québec en mutation économique et spirituelle ${ }^{76}$ : nécessité du dialogue avec la société, du dialogue entre jeune clergé 
et clergé plus âgé, du dialogue avec les tenants d'autres croyances et cultures et obligation pour le clergé d'une présence tangible au monde autant que de collaboration avec le laïcat. Le franciscain déplore le manque de préparation des clercs autant que des laïcs faute d'une vraie faculté de sciences religieuses et de théologie «librement tournée vers la recherche, décloisonnée des barrières scolastiques du Moyen Âge et décidément ouverte aux problèmes religieux de notre temps comme à toutes les catégories d'étudiants et d'étudiantes ${ }^{77}$ ». Il dénonce aussi l'excès de cléricalisme qui marque les cadres d'action catholique et d'apostolat. Gonzalve Poulin se montre tout à fait moderne en considérant la liberté d'action dont dispose l'Église, et qui est due au régime de séparation d'avec l'État, comme l'une des conditions favorables à l'adaptation de l'Église du Québec au monde de ce temps et à la propagation du message chrétien. Effectivement, l'achèvement de la séparation de l'Église et de l'État s'accomplit dans la reconnaissance des minorités et des groupes religieux avec les fonctions qui leur sont propres ${ }^{78}$. Citant, entre autres références, Louis O'Neill et Richard Arès, Gonzalve Poulin incite donc l'Église à combler le décalage entre tradition et renouveau, à se débarrasser de certaines reliques du passé pour embrasser une politique de "coopération démocratique avec un laïcat mieux préparé aux tâches profanes qui lui reviennent ${ }^{79} »$. Cette incitation est conforme à l'objectif d'intégration active des laïcs à la vie de l'Église voulu par Vatican II. C'est aussi ce que préconisent les revues Relations et Maintenant.

Obéissant à son mandat de publication scientifique, la revue offre aussi des articles au contenu à la fois historique, théologique et sociologique qui, sans référence directe à l' $A g$ giornamento et souvent publiés avant l'événement proprement dit, mettent en cause l'Église-institution. C'est le cas des textes de C.J. Eustace, laïc converti au catholicisme une tren- 
taine d'années auparavant. L'un d'eux s'intitule «Catholics and Protestants in a Secularised World", titre tout à fait éloquent. L'auteur y déplore ce qu'il appelle le "ghetto complex $^{80}$ " de l'Église catholique, c'est-à-dire une mentalité défensive issue de la Réforme, et décèle une nette dichotomie entre le spirituel et le temporel. Ce texte œcuménique, qui insiste aussi sur la fraternité inhérente au christianisme, bien qu'il n'aborde aucunement la question conciliaire, n'est pas moins d'une criante actualité. Le mot dialogue y est nettement sous-entendu et cela démontre éloquemment le souci de compréhension entre groupes linguistiques et religieux qui tenaille la revue. Appliqué au Québec, l'article prend tout son sens, foi catholique et langue française y étant le plus souvent liés tandis que les protestants sont majoritairement de langue anglaise. Dans «Religion, Scientific Revolution, and Social Schizophrenia ${ }^{81}$ ", Eustace traite de l'affrontement religionmodernité et s'efforce d'évaluer l'avenir de la religion dans le monde sécularisé qui est le nôtre. L'intérêt porté au concile Vatican II lui semble indicateur de la pertinence de la religion dans le monde moderne.

En général, la revue démontre que le père Gaudron et ses collaborateurs, franciscains et autres, sont prêts à accueillir favorablement l'Aggiornamento, à entamer le dialogue souhaité par Jean XXIII, mais que, à la clôture du Concile, ils sont encore loin de soupçonner l'ampleur des bouleversements à venir. Plus tard, les textes de Jean Goulet, par exemple, seront empreints d'un optimisme que la revue Maintenant ne partagera guère. Dans Culture, l'examen critique des actions de l'Église est à toutes fins utiles inexistant. Par ailleurs, même si les articles concernant directement ou indirectement les changements en cours sont beaucoup plus rares que dans $R e-$ lations et Maintenant, il y a possibilité de trouver dans la revue 
du père Gaudron des indices de la connaissance qu'ont les Franciscains de l'actualité religieuse et sociale.

La réception faite à l'Aggiornamento est donc positive dans la mesure où les rédacteurs se montrent conscients de l'urgence pour l'Église de s'adapter au monde contemporain. Sans nécessairement prendre position en faveur de réformes données, la revue adopte une attitude de confiance envers les capacités d'adaptation de l'Église, ce que j'interprète comme une ouverture au progrès. Loin de refléter une attitude d'éloignement du monde, Culture est plutôt l'expression d'une réelle sensibilité des Franciscains à l'univers dans lequel, malgré la vie monastique qui est la leur, ils évoluent. Après 1966, les effets de l'Aggiornamento et de la sécularisation se font sentir dans le contenu de Culture qui s'y adapte tout autant que les autres revues.

Quant à Maintenant, les exemples proposés donnent une idée de l'esprit libéral qui s'en dégage, la revue se faisant avant tout l'interprète d'espoirs, d'attentes, de constats. Le virage annoncé par Vatican II est accepté mais l'avenir démontrera à quel point l'autoritarisme auquel se cramponne obstinément le magistère freinera l'évolution attendue.

\section{L'après-Concile}

Relations aura le mérite de consacrer un numéro spécial à l'après-Concile, lequel a l'apparence d'un véritable tournant parce que des laïcs s'y expriment de concert avec les clercs. Dix articles y font le point, traitant de renouveau pastoral et liturgique, de la place des prêtres et religieux dans l'Église de demain, de l'engagement du laïcat et, par la plume du jésuite Jacques Lewis, de l'importance d'un dialogue à la fois pastoral et intellectuel entre clercs et laïcs. En réalité, la plupart des articles de ce numéro-charnière de Relations, qui proviennent notamment des Claude Ryan, Jacques Grand'Maison, 
Fernand Dumont, que l'on verra également collaborer à Maintenant, indiquent une tendance au progressisme et une claire acceptation du dialogue clercs-laïcs.

Il n'en demeure pas moins que les années postérieures à Vatican II ne seront pas de tout repos. En fait, les difficultés ne font que commencer et les débats sur la contraception, l'avortement et le divorce n'en sont qu'un exemple. Le pire sera la désaffection, laquelle, selon Raymond Lemieux et JeanPaul Montminy, n'est pas nécessairement la conséquence du Concile mais celle «du processus de modernisation qui passe par l'urbanisation des rapports sociaux et qui a fait des années soixante un temps de rupture culturelle pour les Québécois, transformant leur mentalité et changeant les références faisant autorité dans la culture ${ }^{82} \%$.

La matière concernant la mise en application des recommandations du Concile est abondante et ne peut être dissociée de la crise religieuse qui secoue le monde occidental et particulièrement le Québec. Il y a, dans Relations, des articles qui font le point sur l'expérience conciliaire, sur la place des laïs dans l'Église, sur le renouveau liturgique et autres sujets directement liés à l'Aggiornamento. Il y en a aussi sur le célibat des prêtres, la crise du sacerdoce, la montée de l'athéisme chez les jeunes Québécois, la révolution culturelle en cours. L'Église ne joue plus le rôle d'encadrement qui était le sien et cela parait. La Révolution tranquille lui a ravi son rôle de suppléance, elle perd les hôpitaux, elle perd l'école et n'a plus à défendre que la confessionnalité des écoles publiques. Il lui reste la paroisse et c'est justement là que «la modernité va frapper sans complaisance la culture catholique québé$\operatorname{coise}^{83} »$ : voilà que les vocations baissent, que des prêtres défroquent, que l'assistance aux offices diminue. Selon Lemieux et Montminy, le modèle rural de la communauté paroissiale naturelle résiste mal à l'urbanisation massive et à 
la transformation des rapports sociaux qui en découle: " la religion est devenue un univers social en concurrence avec les autres ${ }^{84}$ ». Il y a aussi que la chrétienté québécoise était mal préparée au virage effectué par l'Église dans le cadre de Vatican II. C'est une réalité qui se dégage petit à petit de la revue Relations. Les collaborateurs chevronnés, comme Luigi d'Apollonia, Marcel Marcotte, Richard Arès, chercheront tant bien que mal à disséquer la crise alors que de plus jeunes recrues, tels Julien Harvey, Roger Blanchette, Jacques Grand'Maison, Pierre Lucier en mesureront l'ampleur avec lucidité et en comprendront mieux les causes.

L'on constatera, au fil des pages qui mènent à 1970 , que l'invitation faite par Vatican II aux laïcs, qui sont le « ferment de la société ${ }^{85} »$, de participer au témoignage de vie ou de sainteté qui était un des thèmes majeurs du Concile, n'est pas facile à concrétiser. Les clercs auront du mal à " partager avec les laïcs le sacerdoce de l'Église ${ }^{86}$ " alors que les laïcs engagés se montreront exigeants, voudront participer aux décisions. Cela ressemble au rapport collégial que souhaitent entretenir les assemblées d'évêques avec Rome. Julien Harvey, S.J., dans un article qui traite de la crise du sacerdoce dans le cadre de la révolution culturelle en cours, expose très bien le drame qui se joue. L'un des facteurs de cette crise fait partie des retentissements du Concile, les prêtres se sentant désormais coincés entre l'épiscopat, à qui le Concile «a redonné une vive conscience de [son] rôle, de [son] identité et de [ses] relations collégiales ", et le laïcat qui s'affranchit et prend conscience de sa place, de son identité, de son rôle. La situation sociale du prêtre, ses fonctions sacerdotales et sa formation sont aussi contestées. Les attitudes face au changement seront diverses : conservatisme des uns, prudence des autres, progressisme radical chez certains, lequel ira parfois jusqu'à la rupture. Le désarroi de ces prêtres qui «se sentent 
devenir inutiles et incapables de rejoindre une société qui leur ferme la porte ${ }^{87}$ » est bien identifié dans les pages de Relations.

La confusion du clergé est une question qui va de pair avec celle de la place de l'Église dans un monde sécularisé et là-dessus un article est à signaler qui illustre la convergence progressive des revues Relations et Maintenant. Il s'agit du commentaire fait par le jésuite Roger Blanchette d'une série de conférences du dominicain Christian Duquoc, collaborateur assidu de Maintenant. Pour Duquoc, le passage d'une civilisation sacrale à une civilisation profane est positif car, pour l'Église, il est une chance de se dégager de ses rôles de suppléance pour mieux se consacrer à l'annonce de l'Évangile et assurer une présence prophétique. Cela représente la perte de chrétiens non convaincus, la fin du cléricalisme et de la christianisation par pression sociale mais c'est aussi l'occasion, pour l'Église, de se débarrasser « de toutes ses compromissions avec les pouvoirs politique, économique et social ${ }^{88} »$. Le jésuite Blanchette trouve profondément théologique la pensée du dominicain Duquoc.

La sécularisation de la société québécoise est d'ailleurs une réalité dont Richard Arès, qui en fera le bilan en 1970, estime qu'elle est " notre plus visible signe des temps ${ }^{89}$ ». Il y demande surtout aux chrétiens de faire en sorte que la société sécularisée demeure ouverte aux valeurs religieuses et aux manifestations de l'esprit chrétien. Richard Arès se sert de la constitution Gaudium et Spes pour "arriver à déterminer une attitude qui mérite le qualificatif de chrétienne tant à l'égard de la sécularisation en général ${ }^{90}$ " que de la décléricalisation, la déconfessionnalisation et la déchristianisation.

Dès 1966, la règle du célibat des prêtres est sujet d'actualité, beaucoup la jugent dépassée et si le Concile ne s'y est pas directement attardé, les décrets Presbytorum ordinis et Optatam totius sur la formation, la vie et le ministère des prê- 
tres ont à la fois confirmé et renouvelé la doctrine traditionnelle. L'encyclique Sacerdotalis calibatus également, à partir d'arguments tirés de la Bible, de la théologie et de l'histoire de l'Église ${ }^{91}$. Deux des articles de Relations qui en traitent sont de la plume de Marcel Marcotte, S.J., deux autres de Georges Robitaille, S.J., et ils sont unanimes : le célibat sacerdotal est encore la voie à suivre. Il est d'ailleurs intéressant de comparer la vision de Marcel Marcotte avec celle du dominicain J.M.R. Tillard qui, dans un même numéro de 1966, expriment leur point de vue respectif. Le père Marcotte, s'en remettant à la théologie pessimiste des Pères de l'Église concernant le mariage, table sur la supériorité de l'état de virginité qui permet la consécration totale à Dieu. Par le sacrement de l'Ordre, le prêtre, devenu propriété exclusive de Dieu, doit s'y consacrer sans réserve. Ce qui n'est pas "une exigence du sacerdoce au sens strict ${ }^{92} "$ - et le père Tillard est d'accord là-dessus - est toutefois conforme à la tradition catholique même si certaines dérogations sont permises en Occident et que le célibat n'est pas obligatoire en Orient.

Le père Tillard ne prend pas nettement position mais cherche à clarifier le problème posé par les abandons et par le célibat sacerdotal. Sa réflexion le mène d'abord à identifier une crise réelle et grave, puis à proposer une solution. À son avis, les sorties traduisent un mal profond lié au style de vie difficile et anormal imposé au prêtre et dont la solitude n'est qu'une des faces. Mais le mariage, qui est aussi un risque, n'est pas nécessairement une panacée. La solution qu'il propose est basée sur deux principes : d'abord la distinction à faire entre le célibat sacerdotal et le vœu de chasteté du religieux, distinction que le père Marcotte évite de faire. Dans le premier cas, "le vœu de chasteté du religieux appartient à l'essentiel même de la profession religieuse entendue comme don total et inconditionné de soi au Père ${ }^{93}$ ». Dans le cas du 
prêtre diocésain, le célibat est lié à la fonction et vise somme toute à la faciliter en libérant le prêtre des obligations imposées par le mariage et la famille. Le second principe est que le célibat, valeur toutefois importante, n'est pas de soi essentiel au sacerdoce. Le père Tillard propose donc une solution à laquelle, théologiquement, rien ne s'oppose et qu'il juge préférable au célibat à tout prix : permettre le mariage à certains après l'épreuve de quelques années de ministère. Cela permettrait peut-être de conserver de bons prêtres et découragerait les vocations temporaires. Le père Tillard, qui est membre d'un ordre religieux, ne remet donc pas en question son propre célibat.

L'on identifie également la montée de l'indifférence religieuse, voire de l'athéisme, tout en cherchant des solutions, comme le dialogue, le renouvellement de l'enseignement, mais sans trop comprendre les raisons profondes du déclin de la foi qui sont liées à ce que Lemieux et Montminy appellent la « conscience de vivre dans un monde diversifiée ${ }^{94}$. Les Québécois, bien qu'attachés à l'héritage catholique, ne le perçoivent plus comme porteur de leur identité.

Julien Harvey se montre assez près de ce que l'on pourra lire dans Maintenant, de la plume de son homonyme Vincent Harvey. À son avis, la réaction contre les institutions qui se produit au Québec est « un des traits majeurs de la quête de notre identité ${ }^{95}$ » et l'évolution de notre christianisme devra maintenant se faire à partir des propres racines de notre sécularisation : fin du christianisme contraint et acquisition de la liberté essentielle à une foi véritablement vécue, remise en question des institutions dans un but de conversion à une véritable vie chrétienne communautaire. Lorsqu'on lui demandera s'il existe un avenir pour le sacré, Julien Harvey répondra oui, mais un sacré critique, exigeant une lecture des expériences humaines, dans un milieu sécularisé qui a pris cons- 
cience «de [son] entière responsabilité et de [sa] croissante maitrise du monde ${ }^{96} \%$.

Jacques Grand'Maison, pour sa part, constatera que les réformes liturgiques et catéchétiques s'essoufflent, que la crise sacerdotale s'aggrave, que les structures de l'Église sont ébranlées, que les difficultés de toutes sortes se multiplient. "C'est comme si, écrira-t-il, l'Église ne parvenait pas à sortir d'ellemême, à prendre vis-à-vis d'elle-même une certaine distance critique, pour se rénover et redevenir un signe lisible et compréhensible pour les hommes d'aujourd'hui' ${ }^{97}$. » C'est presque un constat d'échec du Concile. Or, continue-t-il, sans la reconnaissance des «empreintes idéologiques » qui sous-tendent notre perception de l'Église, de la vie chrétienne, de la théologie, de nos institutions èt de nos débats, tous les efforts, synodes et conciles seront vains ${ }^{98}$. Cette réflexion mène Jacques Grand'Maison à se demander si la société profane et l'Église sont des univers parallèles, opposés ou convergents, si nous devons " vivre une phase de dissociation, pour mieux assurer l'autonomie et le développement de l'un et de l'autre", si nous sommes mûrs pour de nouvelles articulations, s'il existe des liens valables entre ces univers et quels sont les obstacles à affronter ${ }^{99}$. À défaut de réponse il y a reconnaissance d'un aspect capital de la crise sévère qui se produit et identification d'une révolution culturelle qui affecte grandement l'Église puisqu'elle se définit somme toute comme l'invention de nouveaux modèles qui correspondent mieux à la réalité que ce que l'Église peut encore offrir. Lui qui alors fait partie de la Commission d'étude sur les laïcs et l'Église québécoise (Commission Dumont) constatera, à la lumière des réactions des progressistes autant que des intégristes devant la Commission, que l'une des carences graves de l'Église, dans le contexte de révolution culturelle, a été de n'avoir pas eu recours à une pédagogie du changement. 
Somme toute, la revue Relations parait tout à fait réceptive à l'endroit des décisions conciliaires et prête à voir l'Église les assumer. Mais l'enthousiasme du renouveau est tempéré par la montée d'une angoisse de plus en plus palpable devant une crise très profonde que l'on essaie de comprendre et de solutionner sans trop y parvenir. Oui, les vocations sont en baisse, oui, les prêtres, frères enseignants, religieuses s'en vont ${ }^{100}$, oui les Québécois se désintéressent d'une religion qui a perdu de sa crédibilité et la question posée ci-haut par Jacques Grand'Maison prend tout son sens : il semble vraiment que nous soyons en phase de dissociation et que cela s'apparente à l'idéologie du changement propre à la modernité.

Du côté de Culture, alors que le Concile est chose du passé, que le réveil de la société québécoise est accompli et que des problèmes majeurs se posent à l'Église, le franciscain Jean Goulet proposera un tour d'horizon réaliste de la situation, lequel est en conformité avec ce que l'on a pu lire ailleurs, notamment avec les propos de Gonzalve Poulin concernant la participation active des laïcs à la vie de l'Église. Cela commence par l'identification des « signes des temps » dans l'Église et la société québécoise, lesquels constituent le creuset de la crise religieuse en cours. Conséquences du réveil de la société québécoise, les signes des temps qui la touchent, et touchent l'Église par ricochet, s'appellent socialisation, décléricalisation, sécularisation. Jean Goulet en cherche les aspects positifs. Ainsi écrit-il de la socialisation que, tout en provoquant « la baisse ou la perte d'une foi tranquille ${ }^{101}$ », elle déclenche une remise en question et provoque de nouvelles expressions de foi. La socialisation, telle qu'il l'entend, est le résultat du passage d'une société rurale à $65 \%$ à une société urbaine à $75 \%$. Le changement de vie que cette mutation entraîne comporte son lot d'inquiétudes et d'incertitudes, suscite " de nouveaux rapports humains, de nouveaux besoins, 
sans garantir du même coup la sauvegarde de l'individu, le respect et la dignité des valeurs humaines et chrétiennes ${ }^{102}$ ».

De la décléricalisation, Jean Goulet note qu'elle a donné aux clercs l'occasion de comprendre qu'ils sont appelés à servir l'homme et non à le dominer. Maintenant discutera beaucoup de la difficulté pour l'Église, pour le magistère surtout, à se mettre en état de service et y verra une cause de l'échec du Concile. Quant à la sécularisation, Jean Goulet écrit qu'en plus de préciser les responsabilités des laïcs dans l'Église, elle a amené les clercs à s'interroger sur leur propre rôle et, par le biais du Concile, a conduit l'Église à renouveler sa liturgie, sa catéchèse et sa pastorale. C'est dans la logique de ce qu'en dit le grand théologien jésuite Karl Rahner, qu'elle « ne signifie pas premièrement un monde sans relation avec Dieu en théorie et en pratique, mais désigne le "développement du monde (en tant que création de l'homme)" "103" ".

Les propos de Jean Goulet n'offrent rien de nouveau pour qui a parcouru la littérature sur le sujet mais dans le contexte d'une revue donnée, ils constituent le bilan objectif d'une situation qui paraît définitive et qui consacre l'éthique personnaliste. Comme la plupart de ses collègues jésuites et dominicains, Jean Goulet se réjouit de ce que le plus important signe des temps est dans la reconnaissance « de la valeur primordiale de la personne sur les institutions ${ }^{104} »$. Il insiste aussi sur ce que la constitution Gaudium et Spes propose une redécouverte des valeurs humaines et terrestres, reconnaît une valeur chrétienne aux activités temporelles « et aux valeurs humaines assumées par l'homme un intérêt positif ${ }^{105}$ ». Cela représente tout de même, de la part de Vatican II et par conséquent de l'Église, une réussite magistrale qui transcende l'autoritarisme obstiné de la hiérarchie sur lequel Maintenant insistera beaucoup. En admettant plus loin que le retour à un ordre sacralisé n'est plus possible, en constatant que « le salut 
en Jésus-Christ doit passer par l'homme tout entier et le rejoindre là où il se trouve » et que "l'action de l'Esprit, dans une société pluraliste, se laisse découvrir à l'intérieur comme à l'extérieur de l'Église ${ }^{106}$ ", Culture joint sa voix, par le discours de Jean Goulet, à celle des clercs les plus progressistes. Dans un ultime article, Jean Goulet cherchera des solutions aux problèmes engendrés par la socialisation et par la baisse de la foi, surtout chez les jeunes qui sont également les premiers à contester l'Église. Pour réveiller la foi et la nourrir, il propose la constitution de communautés évangéliques et missionnaires. C'est bel et bien ce que proposait Vatican II, événement que René Baril, O.F.M., qualifie de "gigantesque débloquage $\mathrm{e}^{107}$ » et de première étape d'un travail de longue haleine qui doit conférer à l'Église un rôle plus prophétique que jamais.

La revue Maintenant, pour sa part, verra avec inquiétude l'Église post-Vatican II se diriger vers une crise du christianisme se manifestant notamment par l'échec de nombreux mariages, une baisse des vocations, une remise en question du célibat sacerdotal et des défections dont la cause majeure, selon Jacques Grand'Maison, réside dans une perte de confiance progressive des clercs, des religieux et des laïcs en l'institution ecclésiastique ${ }^{108}$. Cette perte de confiance résulte de l'autoritarisme du magistère et du durcissement dogmatique que le débat sur la contraception illustre avec éloquence. En 1969, une fois le débat sur l'encyclique Humana Vita définitivement clos, le directeur de Maintenant constatera que l'équilibre cherché par les travaux conciliaires consistant à mettre le magistère à sa place, qui en est une de serviteur ${ }^{109}$ ", semble rompu. Il ajoutera que

la façon dont le Pape a procédé, en particulier dans la question de la régulation des naissances, nous semble tout à fait le contraire de ce que doit être la forme 
d'exercice de l'autorité dans l'Église post-conciliaire et dans l'Église de demain composée d'hommes habitués à la démocratie et à la participation ${ }^{110}$.

Le bilan effectué dans le centième numéro de Maintenant rend compte d'une situation dont on retient que pour une partie des Québécois catholiques dont la culture était la religion et la religion la culture, le désarroi est complet, le ciel s'est effondré et on ne l'a pas remplacé. Pour les autres, une nouvelle culture s'est substituée à la religion. Jacques Grand'Maison proposera donc « de nouveaux consentements collectifs ${ }^{111}$ », un idéal d'ouverture aux incroyants, d'accueil aux pauvres, de conversion à l'Évangile. L'on retient de cette revue qu'elle offre aux clercs et au laïss, qui y jouissent d'une grande liberté d'expression, la possibilité de dialoguer sur un pied d'égalité dans le but d'assainir l'interaction entre l'Église enseignante et l'Église enseignée.

\section{La régulation des naissances}

S'il est un sujet qui illustre à merveille la polarité idéologique opposant Jésuites et Dominicains, c'est bien le contrôle des naissances et les revues Relations et Maintenant en sont de bons transmetteurs. Mais il importe a priori de préciser que si un débat sur la contraception oppose Relations et Maintenant, c'est parce que l'encyclique Humana Vita n'est pas considérée comme "l'expression du magistère infailli$\mathrm{ble}^{112} »$.

En matière de vie conjugale et de contrôle des naissances on avait signalé la démesure des attentes des pays occidentaux. La désillusion, à la parution de l'encyclique Humana Vita, le 25 avril 1968, est proportionnelle à l'étendue de ces attentes. Paul Christophe explique que cette encyclique illustre le dilemme de Paul VI puisqu'elle « révèle la continuité de l'exercice non collégial du magistère », le pape ayant peu tenu 
compte de la Commission pontificale chargée de l'étude des problèmes de la famille et ayant utilisé des citations de la constitution pastorale Gaudium et Spes émanant d'interventions de la minorité "présentées comme la ligne de pensée du document conciliaire ${ }^{113} »$. Le jésuite Marcel Marcotte, dans une réponse à ceux qui refusent de se rallier aux décisions d'Humana Vita, expliquera aux lecteurs de Relations, à l'automne 1968, que c'est par prudence que Paul VI avait dessaisi les Pères conciliaires de l'examen du problème de la contraception et que s'il avait pris, au moment de rédiger l'encyclique, "le contrepied de l'opinion majoritaire qui s'était fait jour au sein de la Commission d'experts mandatés pour l'assister ", c'est que les opinions exprimées par cette majorité ne faisaient pas le poids face " aux objections de la minorité $^{114} »$. L'article du père Marcotte insiste sur le devoir d'obéissance des catholiques et sur la nécessité pour l'Épiscopat de réaliser la collégialité en se ralliant à la décision du Saint-Père. La revue Maintenant aura une autre vision des choses et les André Charbonneau, Pierre Saucier et Hélène PelletierBaillargeon ${ }^{115}$ verront dans l'évocation du mot magistère une référence à la seule autorité papale et estimeront qu’à la limite le mot Église se confond lui-même avec celui de pape. Ils percevront donc dans l'encyclique la perpétuation du dualisme enseignant-enseigné et de la passivité des laïcs devant l'autorité du magistère.

En décembre 1966, Vincent Harvey, O.P., nouveau directeur de Maintenant, consacre un texte à l'évolution de la théologie du mariage. Le propos de cet exposé permet de mieux comprendre les enjeux du débat et il importe de s'y pencher en passant toutefois par une parenthèse qui concerne Relations. Ajoutons pour notre gouverne que le père Harvey, qui a étudié à fond la philosophie augustinienne et connait par conséquent la conception qu'avait ce Père de l'Église de 
la femme et de la sexualité, possède une large expérience pastorale auprès des couples mariés et se dira un jour "saisi par l'énorme hiatus qui existe entre l'amour concret vécu par ces chrétiens mariés et le concept trouble, rapetissé et légaliste que la théologie traditionnelle nous propose pour leur servir de guide ${ }^{116} »$. Cette phrase soulève le problème de l'opposition entre la conception médiévale des fins du mariage et celle qu'introduit la modernité. Une fois clarifiées ces notions qui démontrent l'humanité, donc la faillibilité, de l'Église-institution, l'attitude tolérante adoptée par Maintenant à l'endroit de la contraception se justifiera d'elle-même. La revue Relations se montre plutôt laconique en ce qui concerne les origines gréco-romaines de la théologie du mariage et son évolution, peut-être parce que le vœu d'obéissance, auquel est tenu chaque jésuite et qui exige même "l'obéissance de jugement ${ }^{117}$ ", fait obstacle à ce genre de rétrospective historique susceptible de semer le doute quant au bien-fondé de la politique vaticane. Joseph d'Anjou, S.J., fait bien allusion, dans une série d'articles consacrés à la régulation des naissances en 1963 et 1964, au dualisme platonicien et au pessimisme augustinien. Beaucoup en auraient conclu à la malignité du corps et de la sexualité, ce que déplore le père d'Anjou, qui toutefois ne remet pas en question la théologie patristique, sinon pour endosser la réinterprétation que l'Église est en voie de faire et qui concède à l'amour entre époux sa juste place. Son discours prudent découle de l'attachement des Jésuites à la hiérarchie et à l'autorité et de leur fidélité inconditionnelle au vœu d'obéissance qui constituent manifestement des entraves majeures au progressisme.

L'article de Vincent Harvey est découpé en deux parties, dont la première décrit les perspectives anciennes et la seconde celles qui s'ouvrent grâce aux progrès de la théologie et aux orientations contenues dans un chapitre du Schéma 
XIII intitulé « Dignité du mariage et de la famille ». La théologie dualiste développée par les Pères de l'Église s'inspire fortement de l'Antiquité gréco-romaine qui concevait le mariage comme l'union de deux personnes "d'inégale[s] dignité et valeur sociale en vue de la bonne gestion d'un patrimoine et de la procréation d'enfants destinés à prolonger la famille et à peupler la citén ${ }^{118}$ ». La morale stoïcienne qui prêchait l'absence de passion, les mouvements gnostiques, particulièrement le manichéisme, hostiles au mariage, la philosophie néoplatonicienne avec son mépris pour le corps et les passions, ont également orienté la pensée des Pères. À titre d'exemple le père Harvey mentionne la prédication de saint Ambroise concernant la supériorité de l'état de virginité sur l'état de mariage ainsi que la fonction purement procréatrice de la femme. Celle de saint Jérôme pour qui le mariage, «n'est qu'un moindre mal, toléré uniquement pour en éviter un pire : la fornication ${ }^{119}$ ", n'est pas moins réductrice bien qu'il ait dû en admettre l'utilité aux fins de procréation. Quant à saint Augustin, dont Vincent Harvey admet qu'il sut concevoir une théologie mieux équilibrée et structurée que celle de ses prédécesseurs, sa conception de la sexualité est pessimiste par le dualisme qu'elle recèle : d'une part, conception de l'amour conjugal comme réalité spirituelle; d'autre part, justification du désir et du plaisir sexuels par la nécessité de procréer et de prévenir l'adultère ${ }^{120}$. Augustin voit dans le mariage et la procréation la seule raison d'être de la femme et considère comme une faute vénielle l'acte sexuel accompli dans le mariage pour d'autres motifs que la fécondation. Par ailleurs, si le haut Moyen Âge vit se durcir les positions des Pères, Vincent Harvey convient, à la décharge de l'Église, que sa pratique pastorale fut généralement plus souple que sa «systématisation théo$\operatorname{logique}^{121}$ ", les femmes non fécondes (stériles, ménopausées ou hystérectomisées) ayant toujours eu la permission de se marier. 
Cet héritage théologique est revu au vingtième siècle et l'encyclique de Pie XI, Casti connubii, à maints égards conservatrice, présente néanmoins "une vue personnaliste de l'amour conjugal et du mariage " parce qu'elle " ne considère pas strictement dans le mariage l'institution destinée à la procréation et à l'éducation des enfants, mais, dans un sens plus large, une mise en commun de toute la vie, une intimité habituelle, une société ${ }^{122}$ \%. Les mouvements familiaux ont pour beaucoup contribué à stimuler la réflexion sur l'amour conjugal et le mariage. La découverte des périodes de fécondité de la femme constitue également un facteur d'interrogation. Un grand pas sera ensuite fait par le Concile qui remplacera la problématique de fin primaire et fin secondaire du mariage par " valeurs et fins diverses du mariage » ce qui élimine la notion de subordination de l'amour conjugal à la procréation. Le devoir de fécondité sera désormais laissé au jugement des époux d'autant plus que l'Église jugeait déjà acceptables les méthodes de régulation basées sur la continence périodique. Le cardinal Léger aura contribué à cette évolution lui qui, dans le cadre des discussions sur le Schéma XIII, demandera au Concile de reformuler la doctrine du mariage pour que les époux n'aient plus l'impression que l'amour est immolé à l'institution et qu'eux-mêmes ne sont que des moyens au service du bien commun ${ }^{123}$. Le chapitre IV du schéma sur l'Église et le monde voudra y répondre par un renouvellement de la problématique qui présente la question conjugale dans une autre optique que celle de l'opposition entre la fin primaire et la fin secondaire du mariage et qui met « en plus fort relief l'amour et l'entraide mutuels des époux ${ }^{124} »$. Insatisfait, car le schéma ne répond pas suffisamment aux difficultés de l'heure, ne présente pas l'amour conjugal et l'entraide mutuelle comme une fin en soi et n'aborde pas «le problème de la finalité des manifestations d'amour dans le mariage », le cardinal souhaitera 
la proclamation de l'égalité des deux fins du mariage car les époux, dira-t-il, « se considèrent l'un et l'autre non comme de simples procréateurs, mais comme des personnes aimées pour elles-mêmes ${ }^{125}$ \%. Le cardinal, en fait, ne fait qu'espérer la réconciliation des traditions concernant les fins du mariage de sorte que «les fins objectives de l'institution conjugale et les fins subjectives des époux s'harmonisent et se fondent dans une parfaite unité ${ }^{26}$ \%. À l'opposé de la pensée augustinienne, le Schéma XIII présentera donc l'amour conjugal comme union intime de la totalité de deux personnes : corps et âme ${ }^{127}$. La venue d'un enfant apparait désormais comme l'aboutissement de ce don mutuel.

Mais les méthodes de contraception artificielle demeurent inacceptables aux yeux de l'Église et la vraie réponse de Rome les concernant arrive en 1968 sous forme d'encyclique dont le contenu, fidèle aux normes déjà émises par Pie XII, sèmera la consternation, divisera les esprits. Paul VI s'y montre formel : « tout acte matrimonial doit rester ouvert à la transmission de la vie ${ }^{128} »$. Le cardinal Maurice Roy, archevêque de Québec, fait alors parvenir aux curés de son diocèse un communiqué sur l'encyclique, dans lequel il demande l'acceptation confiante d'une doctrine qui condamne des pratiques non conformes à la morale naturelle et chrétienne, qui invite par ailleurs les chercheurs à découvrir de nouveaux moyens légitimes de régulation des naissances et qui confirme que c'est au magistère qu'il revient d'éclairer la conscience des époux par son interprétation de la loi divine. Mais de nombreux fidèles se fieront désormais à leur morale personnelle plutôt qu'à une institution dont, de plus en plus, ils mettent en doute la crédibilité. Des femmes profondément déçues feront part aux journaux de leur désarroi. Simonne Monet-Chartrand, par exemple, s'inquiète de ce que, par le message contenu dans l'encyclique, l'Église se coupe «d'une certaine jeunesse... tout 
en ne faisant pas un pas vers un rapprochement des Églises ${ }^{129}$ " puisque les autres Églises laissent le problème de la planification familiale à la conscience des époux. Une autre, Claire Guillemette, écrira au Devoir qu'aucune religion ne peut plus «se prévaloir de droits de paternité, d'autorité et d'infaillibilité $^{130} »$. C'est par contre à Relations que les Claire Campbell et Marguerite-M. Guérin feront part de leur soumission à la doctrine pontificale, indice que cette revue attire probablement un lectorat plutôt conservateur. Mais Claire Campbell trouve le document à la fois bienfaisant et controversé et se montre de ce fait consciente de la sévérité de l'encyclique, compte tenu des facteurs physiologiques et psychologiques qui influencent le problème de la fécondité, particulièrement l'anxiété à laquelle la régulation basée sur la continence périodique soumet beaucoup de femmes.

Du mois de septembre à la fin de 1968, ainsi qu'en avril et juin 1969 (après quoi on n'en parlera plus), plusieurs éditoriaux et articles de Relations traiteront de l'encyclique mais c'est au jésuite Marcel Marcotte que reviendra la tâche de démontrer l'évolution de la pastorale conjugale et de justifier le discours de Paul VI. Les quatre longs articles qu'il consacre à l'encyclique traitent de l'obéissance catholique, de la pastorale de la fécondité, de la paternité responsable (cela inclut la maternité) et de la liberté de conscience.

Première constatation de Marcel Marcotte après la parution de l'encyclique : Paul VI oppose un non irrévocable et catégorique à la contraception sous toutes ses formes. Un oui, même mitigé, eût constitué une tragédie et jeté le discrédit sur l'Église, compte tenu de ce qu'elle aurait eu à reconnaître s'être trompée par le passé, elle qui est censée interpréter la pensée de Dieu. Par contre cette condamnation n'est pas un article de foi et la question n'engage pas l'infaillibilité de l'Église (au sens technique du terme, précise Marcel Mar- 
cotte), car si tel était le cas, précise-t-il, la question n'aurait été débattue ni au Concile, ni par la commission pontificale chargée de la réexaminer. Les termes employés par le pape dans l'encyclique auraient été différents, ils auraient été "des signes certains et facilement reconnus d'une définition de foi prononcée ex cathedra, en vertu du magistère extraordinaire de l'Église... ${ }^{131}$ » En théorie, un autre pape pourrait contredire la condamnation de la contraception. Le chrétien qui refuse d'en tenir compte ne peut donc être tenu pour hérétique. C'est une question qui regarde le domaine de la moralité dans lequel, de préciser le père Marcotte, « les décisions et les règles de l'Église ne portent pas partout le même caractère de fermeté et d'irrévocabilité $^{132}$ ». L'attitude à adopter pour le chrétien est donc l'obéissance parce que, l'Église étant hiérarchique, le pape ayant reçu du Seigneur le mandat d'y exercer l'autorité nécessaire à sa cohésion, la crise de l'obéissance qui est en cours en menace l'existence. L'obéissance, en l'occurrence, consiste en une démarche visant «à reconnaître la compétence du Magistère et donc du pape qui l'exerce », l'Église s'étant depuis ses origines « reconnue le droit d'interpréter, à titre autoritaire pour les croyants, indicatif pour les incroyants, non seulement les exigences de la loi évangélique, mais celles de la loi naturelle ${ }^{133}$ ». Dans ce contexte les catholiques, par un processus de disponibilité intérieure qui reconnait le droit du pape à juger et constitue une manifestation de foi, se doivent de laisser l'Église trancher les problèmes moraux et de se rallier à un enseignement qui, d'insister le père Marcotte, " participe à l'infaillibilité même de Dieu ${ }^{134} »$. Par contre, les principes de la liberté de conscience entrent en jeu lorsque le croyant, que sa foi oriente vers l'obéissance mais qui reste intimement convaincu de l'inexactitude des vues de l'encyclique, ne peut y adhérer. Autrement dit, et c'est le sujet d'un autre article du père Marcotte, « la contraception est toujours 
un désordre, comme le pape l'affirme, mais elle n'est pas toujours un péché, puisque la conscience peut, de bonne foi, la juger innocente ${ }^{135}$ ». Cette interprétation est substantiellement révolutionnaire parce qu'elle tient compte du facteur de responsabilité individuelle contenu dans la modernité.

C'est sur l'obligation pour les époux chrétiens de suivre leur conscience qu'insiste l'article $\mathrm{n}^{\circ} 50$ de la constitution conciliaire Gaudium et Spes sur la paternité responsable : la régulation des naissances est un droit, parfois un devoir dont les motifs doivent cependant procéder d'un jugement droit, c'est-à-dire de «l'obligation de toujours suivre leur conscience, une conscience qui doit se conformer à la loi divine ${ }^{136} »$. Cela implique la docilité au magistère de l'Église, autorisé à interpréter la loi divine à la lumière de l'Évangile. Marcel Marcotte considère par conséquent que Paul VI, dans son encyclique, n'a fait « qu'expliciter et prolonger ces directives du Concile. Positivement, en faisant de la paternité responsable la norme idéale de la régulation des naissances ; négativement, en refusant de l'associer à la contraception ${ }^{137}$. "

La revue Maintenant exprimera sans équivoque sa déception, voyant dans l'encyclique un retour au catholicisme pré-conciliaire $^{138}$ avec rupture du dialogue de confiance entamé par Vatican II et, en quelque sorte, échec du Concile du moins en ce domaine. Les auteurs de l'éditorial ${ }^{139}$ du numéro d'août-septembre 1968, constatant que de nombreux catholiques utilisent déjà la contraception sans y voir d'incompatibilité avec leur appartenance à la communauté chrétienne, entreverront mal la possibilité d'un retour en arrière. Ils penseront également que l'encyclique marque un tournant important de la vie de l'Église, soit en accélérant la désaffection à l'égard de l'autorité, soit en incitant les laïcs à effectuer, à la lumière de leur expérience personnelle, leur propre lecture et leur propre interprétation de l'Évangile. Dans ce dernier cas, 
peut-être verrions-nous la fin du clivage entre l'Église enseignante et l'Église enseignée et le retour à la communauté originelle.

Il reviendra à André Charbonneau, Pierre Saucier et Hélène Pelletier-Baillargeon de prendre la parole au nom des couples catholiques et de développer intégralement les idées émises dans l'éditorial. Cela démontre encore une fois la différence fondamentale entre les revues Maintenant et Relations, cette dernière n'accordant encore qu'à des clercs le privilège d'exprimer la position de l'Église et par le fait même de perpétuer la communication en sens unique qui prévaut au sein de cette institution. Selon les auteurs du texte l'encyclique " inscrit la vision de Paul VI dans une conception de l'homme et de l'Église diamétralement opposée à celle du Concile ${ }^{140}$ ", Église et papauté se confondant pour mieux perpétuer le dualisme enseignant-enseigné et par là même une vision statique et pessimiste de la communauté des fidèles. Le Concile, au contraire, avait privilégié l'initiative et l'engagement personnel et « à l'argument d'autorité » préféré « le recours à la conscience éclairée $e^{141} »$. Cela impliquait, pour les fidèles, une réforme de leur pensée et des moyens d'action permettant l'instauration de structures démocratiques aptes à favoriser leur participation à la vie de l'Église ${ }^{142}$. Cela représentait également un changement de mentalité de la part des évêques, qui avaient voulu faire du Concile un événement pastoral et s'étaient « refusés à définir des dogmes et à lancer des anathè$\operatorname{mes}^{143} »$. Selon les signataires de l'article, l'encyclique mettait en présence deux problématiques irréconciliables, deux anthropologies, deux ecclésiologies, deux lectures de la Tradition. Il ne restait donc plus aux catholiques qu'à s'en remettre à leur conscience personnelle quant au choix à faire concernant la contraception. 
L'opinion formulée par Vincent Harvey, O.P., est sans équivoque lorsqu'il ajoute, à son article de 1966 :

Si l'on se place dans cette perspective globale et si l'on tient compte de l'unité conjugale comme une des valeurs fondamentales du mariage, je ne vois pas trop comment on pourrait faire une discrimination, du point de vue théologique, entre les diverses méthodes efficaces de régulation des naissances (à l'exception bien sûr des méthodes abortives), dès lors qu'elles permettent aux époux qui sont obligés de limiter les naissances, de s'aimer de la façon la plus épanouissante possible dans telle ou telle circonstance de leur vie conjugale. Les facteurs qui entrent ici en ligne de compte relèvent de la médecine, de la psychologie et des dispositions particulières des époux, mais non, à mon avis, d'un principe moral prétendûment objectif, indépendamment des personnes dans la complexité de leur existence, et qui se nommerait l'intégrité physique de l'acte ${ }^{144}$.

Par contre, à ceux qui reprocheraient à Paul VI de retourner à un catholicisme préconciliaire, Luigi d'Apollonia rétorquera, citant la constitution Lumen gentium :

Une soumission religieuse de la volonté et de l'intelligence est due à un titre spécial au magistère authentique du pontife romain, même lorsqu'il ne parle pas $e x$ cathedra. Son magistère suprême demande à être accueilli avec révérence, les décisions qu'il prend réclament une adhésion sincère, conforme à sa pensée et à sa volonté, telles qu'elles se manifestent soit par le caractère des documents, soit par l'insistance à revenir sur une même doctrine, soit par sa manière de par$\operatorname{ler}^{145}$.

De toute façon, les idées sur la contraception sont faites, les positions sont prises et nulle encyclique ne peut y changer quoi que ce soit. C'est en tout cas ce que constate le do- 
minicain Jean-Paul Audet qui, dans un ultime article sur le sujet, reprend en grande partie les arguments énoncés par les autres : opposition de deux vues et deux langages, distinction floue entre ce qui est méthode naturelle et méthode artificielle, question de l'infaillibilité du pape, remplacement, au fil de l'histoire, de la fraternité des communautés chrétiennes d'origine par un patriarcat hiérarchisé... pour finalement constater une rupture des communications au sein de l'Église. L'encyclique, en tant que genre littéraire, est rigide et solennelle. Elle fait part au public d'une décision prise en haut lieu alors que la communauté chrétienne est plutôt avide d'un enseignement qui tienne compte des diverses situations auxquelles elle doit faire face. Cela ramène encore une fois à la relation à sens unique de l'Église enseignante avec l'Église enseignée de même qu'à la subjectivité et au principe d'autonomie.

\section{$* * *$}

En vérité, Maintenant se montre nettement plus progressiste en matière de contraception que ne l'est Relations, qui visiblement éprouve encore, du moins dans ce domaine, des réticences à l'égard de la collégialité. De plus, au lieu de consulter l'opinion publique, elle se contente de confier l'analyse du problème au seul Marcel Marcotte. Maintenant se distingue par la diversité des interventions et surtout par la parole donnée aux laïs : c'est la différence fondamentale sur laquelle on se doit d'insister. Elle se montre en cela solidement intégrée à la modernité. Le débat provoqué par la contraception et l'encyclique Humance Vito est somme toute un bon indicateur de la difficulté qu'éprouve encore l'Église à s'adapter au monde de ce temps avec ce que cela implique de changements et d'interrogations. C'est un débat intimement lié à l' $A g$ - 
giornamento et qui, à cause de sa visibilité médiatique, méritait d'être traité à part.

Ce que nous révèlent les articles de Relations préfigure les conclusions auxquelles aboutissait, en 1968, le mémoire de maitrise de Pierre Beausoleil qui porte sur les années 19661967, selon lequel ces Jésuites perpétuent la traditionnelle relation clerc-enseignant/laïc-enseigné. L'étude de Maintenant révèle au contraire que les dominicains qui y collaborent, en acceptant d'entamer le dialogue avec les laïcs et en tenant compte de la réalité vécue par les couples mariés, se trouvent à rejeter le monolithisme doctrinal, indépendamment de l'opinion personnelle des clercs. Les Jésuites se refusent à mettre en doute la parole de l'Église alors que les Dominicains, conscients de la réalité sociale, c'est-à-dire du fait qu'une importante proportion de couples catholiques a recours à des moyens de contraception condamnés par l'Église, optent pour le questionnement. En outre ils se montrent fidèles à l'objectif de dialogue et d'engagement qu'ils s'étaient fixé en fondant la revue Maintenant et que le père Bradet explicitait dans le numéro de mai 1962: opter pour des textes «susceptibles de reposer les problèmes et de les réviser dans l'optique $1962^{146} \%$. C'est pour cela qu'ils consentent, en donnant la parole aux laïcs et particulièrement aux femmes, qui après tout sont les premières concernées, à mettre en question la position de l'Église en matière de régulation des naissances et à accorder aux laïcs la pleine responsabilité de leurs actes. Ils se réclament par le fait même de la liberté de presse, autant pour la presse catholique que pour toute autre ${ }^{147}$, alors que les Jésuites, dont l'opinion sur la légitimité de la contraception artificielle est totalement conforme à celle de Rome, n'auraient jamais permis la publication de textes comme ceux qui, des années avant Humanae Vitae, coûtèrent au père Bradet son poste de directeur de Maintenant et dont les auteurs étaient 
Solange Chalvin, Marcel-Marie Desmarais, O.P., et Georges Méthot, O.P. Les Dominicains pour qui, selon Pierre Beausoleil, le conflit Religion-Société se trouve résolu par la réduction du terme Religion à une inspiration plutôt qu'à une institution $^{148}$, se situent donc dans la ligne progressiste. Ce que Pierre Beausoleil veut dire, c'est que l'intégrisme (c'est le terme qu'il emploie), réduit la religion au domaine institutionnel alors que le progressisme évacue, dans la mesure du possible, les institutions sociales de la religion. Le principe de sécularisation, inhérent à la modernité contemporaine, y est donc implicite.

Cette matière révèle donc, de la part des Jésuites, une fidélité à la parole pontificale mais il faut admettre qu'on y perçoit tout de même un assouplissement du conservatisme rigide de l'époque préconciliaire. Le père Marcotte, du moins, s'efforce de faire honnêtement la part des choses mais l'on est en droit de se demander si sa prose n'escamote pas le véritable problème, lequel s'inscrit dans le contexte de révolution sexuelle qui marque ces années, celui des femmes qui portent les enfants, les mettent au monde, les élèvent et vivent dans la crainte que «la méthode » les trahisse le mois qui vient. C'est d'ailleurs dans leur manière d'aborder la question que réside la différence tangible entre position jésuite et position dominicaine, la première tenant surtout compte de la position du magistère et la seconde de la situation dans laquelle se trouvent les femmes et les couples. L'examen de la revue Maintenant est là-dessus révélateur.

Pour ce qui est de l'Aggiornamento proprement dit, c'està-dire des réformes proposées par le Concile, le passage d'un catholicisme à l'autre est synchrone parce que Jésuites, Franciscains et Dominicains se montrent conscients de la nécessité pour l'Église de se détourner du triomphalisme pour se concentrer plutôt sur sa mission évangélisatrice. Ces réfor- 
mes sont accueillies favorablement et cela démontre que Vatican II s'imposait et qu'à maints égards il a réussi ; mais il constitue aussi, aux yeux de nombreux catholiques, des plus libéraux aux plus conservateurs et pour diverses raisons, un échec retentissant. Maintenant le notera avec amertume, Relations vivra la situation avec angoisse tandis que Culture réfléchira à de possibles solutions. Selon Gilles Routhier, le Concile a servi, pour les Québécois, de symbole de changement et de réformes, voire d'instrument de rupture avec le passé. Des journaux comme La Presse, Le Soleil, La Tribune s'en sont même servis " comme visa idéologique pour légitimer le programme de réforme mis alors en avant au Québec ${ }^{149}$ ». Sous cet aspect il est donc indissolublement lié à la Révolution tranquille, surtout si l'on tient compte de l'éthique personnaliste, phénomène dont s'étaient nourris beaucoup des penseurs et des acteurs de la Révolution tranquille, et qui est indissociable du catholicisme contemporain. Le Concile a, ajoute Routhier, modifié le système de gouvernement de l'Église, libéré la parole, stimulé la participation des laics, fait prendre à l'Église conscience de son universalité et représente, parce qu'il s'est refusé à prononcer toute condamnation, « un effort pour entrer en dialogue avec les diverses composantes du monde contemporain ${ }^{150} »$. Mais le plus important est, et ce parce que l'Église a voulu se remettre en question et se réformer, qu'il constitue un véritable acte de foi.

\section{NOTES}

${ }^{1}$ Cet article résume un des thèmes abordés dans Janine Thériault, $D$ 'un catholicisme à l'autre. Trois ordres catholiques au Québec et leurs revues face à l'Aggiornamento et à la Révolution tranquille, 1958-1970, Thèse de Ph.D. (histoire), Université de Montréal, 2003, 420 p.

${ }^{2}$ Georges-Henri Lévesque, Souvenances, tome 2, Montréal, Éditions La Presse, 1988, pp. 176-188. 
${ }^{3}$ Ce débat concerne exclusivement les revues Relations et Maintenant; Culture ne s'en mêle pas même si quelques-uns de ses articles concernant la morale familiale révèlent une position conservatrice. Si la thèse dont est tiré le présent article aborde quatre sujets principaux, soit le nationalisme, la régulation des naissances, la réforme de l'éducation proposée par le Rapport Parent et l' $A g$ giornamento (mise à jour) entrepris par Vatican II, c'est ce dernier sujet que le présent texte doit explorer en y mêlant toutefois la polémique concernant Humana Vita.

+ Pierre Trépanier, « Notes pour une histoire des droites intellectuelles canadiennes-françaises à travers leurs principaux représentants (1770-1970) », Les Cabiers des Dix, $\mathrm{n}^{\circ} 48$ (1993), p. 140.

${ }^{5}$ Ibid., p. 151.

"Alain Touraine, Critique de la modernité, Paris, Fayard, 1992, p. 15.

${ }^{7}$ Ibid., p. 240.

${ }^{\rtimes}$ Ibid., p. 241. Sujet : "le mot entre dans le vocabulaire philosophique au début du XIX ${ }^{\mathrm{e}}$ siècle d'après l'allemand Subjekt (Kant) de même origine, désignant l'être pensant, considéré comme le siège de la connaissance, par opposition à objet. » Le Robert. Dictionnaire historique de la langue francaise, Paris, Dictionnaires Le Robert, 1992, p. 2045.

"Alain Renaut, «Liberté, égalité, subjectivité », dans Alain Renaut, dir., Histoire de la philosophie, tome 2, Naissances de la modernité, Paris, Calmann-Lévy, 1999, pp. 7-23.

1" Joachim Kopper, « La connaissance objective chez Maurice Blondel », dans Dominique Folscheid, dir., Maurice Blondel une dramatique de la modernité, Paris, Éditions universitaires, 1990, p. 96.

"Johann Figl, "Sécularisation", dans Peter Eicher, dir., Nouveau dictionnaire théologique, Adaptation française sous la direction de Bernard Lauret, Paris, Éditions du Cerf, 1996, p. 900.

12 André Vachon, "Une tradition à inventer », Littérature canadienne-franfaise, n 1-10, Presses de l'Université de Montréal, 1969, p. 277.

${ }^{13}$ Léon Dion, La révolution déroutée, 1960-1976, Montréal, Boréal, 1998, p. 25.

${ }^{14}$ E.-Martin Meunier et Jean-Philippe Warren, «L'horizon personnaliste de la Révolution tranquille », Société, nos 20-21 (été 1999), p. 382.

${ }^{15}$ Gérard Cholvy et Yves-Marie Hilaire, Histoire religieuse de la France contemporaine, tome 3, Toulouse, Privat, 1988, p. 24. 
${ }^{16}$ Meunier et Warren, loc. cit., p. 361.

${ }^{17}$ Cholvy et Hilaire, op. cit., p. 25.

${ }^{18}$ Gérard Cholvy, La religion en France de la fin du XVIII' siècle à nos jours, Paris, Hachette, 1991, p. 114.

${ }^{19}$ Michel Winock, Le siècle des intellectuels, Paris, Éditions du Seuil, 1999, p. 525.

2" Selon Pierre Trépanier, l'abbé Lionel Groulx qui, dès ses dernières années de collège se préoccupait de la place du laïcat dans l'Église, a lui-même subi linfluence de Maritain et sa bibliothèque renferme de nombreux ouvrages du philosophe français (communication personnelle).

${ }^{21}$ Cholvy, op. cit., p. 27.

${ }^{22}$ Yves Cloutier, «L'influence de Maritain : un déterminant de la réception de Vatican II au Québec ", dans Gilles Routhier, dir., L'Église canadienne et Vatican II, Montréal, Fides, 1997, p. 406.

${ }^{23}$ Simon Lapointe, L'influence de la gauche catholique francaise sur l'idéologie de la CTCC-CSN de 1948 à 1964, Thèse de M.A. (histoire), Université de Montréal, 1994, p. iii.

${ }^{24}$ Luigi d'Apollonia, cité dans Jean-Claude Dupuis, «La revue Relations et le Concile Vatican II ", Les Cabiers d'bistoire du Québec au XX $X^{\natural}$ siècle, $\mathrm{n}^{\circ} 6$ (automne 1996), p. 34.

${ }^{25}$ Cholvy et Hilaire, op. cit., p. 266.

${ }^{26}$ André Naud, dans Brigitte Caulier et Gilles Routhier, dir., Mémoires de Vatican II, Montréal, Fides, 1997, p. 70.

${ }^{27}$ M.-C. Matura, «Le renouveau biblique contemporain et sa signification », Culture, vol. XXI (1960), pp. 3-12.

${ }^{28}$ Jean Lacroix, "Ce qu'un laïc attend du concile », Relations, vol. 22, n 262 (octobre 1962), p. 273.

${ }^{29}$ Jean Martucci, " Ce que les catholiques attendent du concile ", Maintenant, vol. 1 (mars 1962), p. 90.

${ }^{30}$ Ibid., pp. 90-91.

${ }^{31}$ Daniel Pourchot, « Ce que les protestants attendent... », Maintenant, vol. 1 (mars 1962), p. 91. 
${ }^{32}$ Denise Robillard, Paul-Émile Léger, 1950-1976 : l'évolution de sa pensée, Montréal, Hurtubise HMH, 1993, p. 188.

${ }^{33}$ Ibid., p. 240.

${ }^{34}$ Guy Rocher, Le Québec en mutation, Montréal, Hurtubise HMH, 1973, p. 207.

${ }^{35}$ Nouveaux mouvements religieux, croyance à la réincarnation, groupes de croissance spirituelle et religion à la carte. Les ouvrages sur le sujet sont nombreux, dont une publication de la théologienne Suzanne Rousseau, L'immortalité de l'âme en question, Montréal, Fides, 2001, 246 p.

${ }^{36}$ Paul-André Linteau, René Durocher, Jean-Claude Robert, François Ricard, Histoire du Québec contemporain, tome II, Le Québec depuis 1930, Montréal, Boréal, 1989, p. 348.

${ }^{37}$ Pierre Beausoleil, Analyse de contenu comparée de deux publications catholiques, Maintenant et Relations : étude des thèmes idéologiques sur le problème de la limitation des naissances, Montréal, Thèse de M.A. (sociologie), Université de Montréal, 1968, p. 24.

${ }^{38}$ Richard Arès, « Notre plus visible signe des temps. La sécularisation de la société québécoise », Relations, vol. 30, n 353, octobre 1970, p. 274.

39 Jacques Valois, cité dans Jean Hamelin, dir., Les Franciscains au Canada, 18901990, Québec, Septentrion, 1990, p. 266.

4" V. Cosmao, « Désaccord et unanimité », Maintenant, $\mathrm{n}^{\text {os }} 43-44$ (juillet-août 1965), p. 256.

${ }^{+1}$ Louis-Nazaire Hamel, "Mater et magistra. Une conception totalitaire du monde social », Culture, vol. XXII (1961), pp. 423-431.

${ }^{42}$ Ibid., p. 425.

${ }^{43}$ Luigi d'Apollonia, «Lettre du Vatican », Relations, vol. 24. n ${ }^{\circ} 286$ (octobre 1964), p. 286.

${ }^{+4}$ Jean Lacroix, «Ce qu'un laïc attend du Concile », Relations, vol. 22, n 262 (octobre 1962), p. 273.

${ }^{t 5}$ Gaëtan Baillargeon, «Les intellectuels québécois et Vatican II », dans Gilles Routhier, dir., L'Église canadienne et Vatican II, Montréal, Fides, 1997, p. 200.

t" Richard Arès, «L'Église et l'État ", Relations, vol. 22, n² 262 (octobre 1962), p. 266. 
${ }^{47}$ Michel Despland, « CEcuménisme et liberté religieuse au Québec », Maintenant, $\mathrm{n}^{\circ} 51$ (mars 1966), p. 101.

${ }^{48}$ Henri-M. Bradet, « Heure des laïcs, horloge des clercs ", Maintenant, $\mathrm{n}^{\circ} 23$ (novembre 1963), pp. 325-328.

${ }^{49}$ P.-A. Liégé, «L’Église de l'autorité ou l'Église de la liberté ? ", Maintenant, $\mathrm{n}^{\circ} 11$ (novembre 1962), pp. 361-362.

${ }^{50}$ Doris Lussier, «L'intégrisme contre la foi », Maintenant, $\mathrm{n}^{\circ} 27$ (mars 1964), pp. 82-83.

${ }^{51}$ La Direction, «Tolérance... », Maintenant, $\mathrm{n}^{\circ} 28$ (avril 1964), p. 144.

${ }^{52}$ Christian Duquoc, «Liberté religieuse », Maintenant, $\mathrm{n}^{\circ} 37$ (janvier 1965), $\mathrm{p}$. 7.

${ }^{53}$ Ibid., p. 8, et Despland, loc. cit., p. 101.

${ }^{54}$ Jean-Paul Vanasse, "La liberté pour quoi faire ?", Maintenant, $\mathrm{n}^{\circ 4}$ 45-48 (automne 1965), p. 292.

${ }^{55}$ Éditorial, « La constitution sur la liturgie », Relations, vol. 24, $\mathrm{n}^{\circ} 277$ (janvier 1964), p. 1.

${ }^{56}$ Jacques Leclercq, "Vers une Église missionnaire », Maintenant, $\mathrm{n}^{\circ} 37$ (janvier 1965), pp. 9-10 et "Peuple de Dieu ", Maintenant, $\mathrm{n}^{\text {os }}$ 45-48 (automne 1965), pp. 282-283.

${ }^{57}$ Pierre Aubailly, « Démocratie dans l'Église », Maintenant, $\mathrm{n}^{\circ} 36$ (décembre 1964), pp. 392-393.

${ }^{58}$ Luigi d'Apollonia, "Primauté et collégialité », Relations, vol. 23, nº 276 (décembre 1963), p. 346.

59 Ibid., p. 346.

${ }^{61)}$ Gregory Baum, « Gouvernement de l'Église et collégialité », Maintenant, $\mathrm{n}^{\mathrm{os}}$ 45-48 (automne 1965), p. 266.

${ }^{61}$ Ibid., p. 266.

${ }^{12}$ Luigi d'Apollonia, "Les trois conciles », Relations, vol. 25, n 297 (septembre 1965), p. 254.

${ }^{6.3}$ "Idées imaginaires sur le Concile », Relations, vol. 23, $\mathrm{n}^{\circ} 276$ (décembre 1963), p. 341.

${ }^{64}$ Paul Doucet, " Galilée à Vatican II », Maintenant, n 36 (décembre 1964), pp. 392-393. 
${ }^{65}$ Luigi d'Apollonia, "Le schéma XIII », Relations, vol. 24, nº 288 (décembre 1964), p. 354.

${ }^{66}$ Idem, "Les trois conciles », Relations, vol. 25, n 297 (septembre 1965), pp. 251-254.

${ }^{67}$ «La question juive », Relations, vol. 24, nº 288 (décembre 1964), p. 346.

${ }^{68}$ Luigi d'Apollonia, "Les non-chrétiens et les Juifs », Relations, vol. 25, $\mathrm{n}^{\circ}$ 300 (décembre 1965), p. 346.

(9) Idem, « Les trois conciles », p. 254.

${ }^{70}$ Idem, « La liberté religieuse et le Concile », Relations, vol. 25, nº 298 (octobre 1965), pp. 284-287.

${ }^{71}$ Ibid., p. 287.

72 Richard Arès, «L'Église au Québec », Relations, vol. 26, n 302 (février 1966), p. 32.

${ }^{73}$ Marcel Adam, «Gauche, droite au concile ? », Maintenant, $\mathrm{n}^{\circ} 27$ (mars 1964), p. 117. Dans cet article Marcel Adam, d'accord avec un jésuite français, le Père Rouquette, juge inadéquats les termes gauche et droite ou progressistes et conservateurs dans le cas des questions ecclésiales ou conciliaires.

${ }^{74}$ Luigi d'Apollonia, «Les trois conciles », Relations, vol. 25, n 297 (septembre 1965), p. 253.

${ }^{75}$ Ibid., p. 253.

${ }^{76}$ Gonzalve Poulin, « Réflexion sur l'Église au Québec français », Culture, vol. XXVI (1965), pp. 256-263.

${ }^{77}$ Ibid., p. 260.

${ }^{78}$ John Hewson, « Secular and Denominational Institutions The Separation of Church and State », Culture, vol. XXVII (1966), p. 147.

79) Poulin, loc. cit., p. 261.

${ }^{80}$ C.J. Eustace, "Catholics and Protestants in a Secularised World ", Culture, vol. XXI (1960), p. 18.

${ }^{81}$ Idem, « Religion, Scientific Revolution, and Social Schizophrenia », Culture, vol. XXVI (1965), p. 17.

${ }^{82}$ Raymond Lemieux et Jean-Paul Montminy, Le catholicisme québécois, Québec, Éditions de l'IQRC, 2000, p. 68. 
${ }^{83}$ Ibid., p. 65.

${ }^{8+}$ Ibid., p. 66.

${ }^{85}$ René Latourelle, « Les laïcs, ferment de la société », Relations, vol. 27, $\mathrm{n}^{\circ} 321$ (janvier 1967), pp. 3-5.

${ }^{86}$ Lucia Ferretti, Brève bistoire du catholicisme québécois, Montréal, Boréal, 1999, p. 163.

${ }^{87}$ Yves Saint-Arnaud, "Quelques prérequis au dialogue pastoral dans un monde sécularisé », Relations, vol. 28, n 327 (mai 1968), p. 152.

${ }^{88}$ Roger Blanchette, «L'Église et les défis de la lä̈cité », Relations, vol. 27, $\mathrm{n}^{\circ}$ 312 (janvier 1967), p. 19.

${ }^{89}$ Richard Arès, « Notre plus visible signe des temps. La sécularisation de la société québécoise ", Relations, vol. 30, n 353 (octobre 1970), pp. 274-277.

${ }^{90}$ Idem, "Sécularisation Québec. Le chrétien face à la sécularisation de la société québécoise », Relations, vol. 30, n 354 (novembre 1970), pp. 300-303 et « Notre plus visible signe des temps. La sécularisation de la société québécoise ", loc. cit.

${ }^{91}$ Georges Robitaille, «L'encyclique Sacerdotalis calibatus », Relations, vol. 27, $\mathrm{n}^{\circ} 319$ (septembre 1967), pp. 227-230.

${ }^{2}$ Marcel Marcotte, "Le célibat des prêtres dans l'optique du Royaume", Relations, vol. 26, n 308 (août-septembre 1966), p. 231.

${ }^{93}$ J.M.R. Tillard, «À propos du célibat des prêtres », Relations, vol. 26, n 308 (août-septembre 1966), p. 236.

${ }^{94}$ Lemieux et Montminy, Le catholicisme québécois, p. 69.

${ }^{95}$ Julien Harvey, «L'homme d'ici et le salut offert », Relations, vol. 28, n 327 (mai 1968), p. 154.

"Idem, «L'avenir du sacré », Relations, vol. 30, n 348 (avril 1970), p. 104.

${ }^{97}$ Jacques Grand'Maison, «L'Église et les idéologies au Québec », Relations, vol. $29, \mathrm{n}^{\circ} 343$ (novembre 1969), p. 293.

${ }^{98}$ Ibid., p. 293.

${ }^{99}$ Ibid., p. 296.

100 « Entre 1962 et 1969, le clergé perd 16\% de ses effectifs, les congrégations 36\% entre 1962 et 1978. » (Lucia Ferretti, Brève histoire du catbolicisme québécois, 
p. 164.) Georges Robitaille estime qu'en dix ans, soit depuis 1956, quelque 10000 prêtres sur 420000 que comptait l'Église universelle, ont demandé à Rome de leur permettre de se marier. Georges Robitaille, "Le célibat des prêtres », Relations, vol. 26, n 304 (avril 1966), pp. 102-103.

${ }^{101}$ Jean Goulet, «Signes des temps et Église du Québec », Culture, vol. XXX (1969), p. 180.

${ }^{102}$ Ibid., p. 180.

${ }^{1113}$ René Baril, "Congrès international de Toronto », Culture, vol. XXVIII (1967), p. 305.

${ }^{1114}$ Goulet, loc. cit., p. 186.

${ }^{105}$ Ibid., p. 187.

${ }^{106}$ Ibid., p. 191.

${ }^{1117}$ René Baril, loc. cit., p. 306.

${ }^{108}$ Jacques Grand'Maison, « Une Église au seuil d'un second souffle », Maintenant, $\mathrm{n}^{\circ} 100$ (novembre 1970), p. 282.

${ }^{109}$ Vincent Harvey, «Quand le pape a parlé, faut-il se taire ? ", Maintenant, $\mathrm{n}^{\circ}$ 85 (avril 1969), p. 99.

110 Ibid., p. 101.

"11 Jacques Grand'Maison, «Une Église au seuil d'un second souffle », Maintenant, $\mathrm{n}^{\circ} 100$ (novembre 1970), p. 284.

$112 \mathrm{H}$. Waldenfels, Manuel de théologie fondamentale, Paris, Éditions du Cerf, 1990, p. 768. La constitution Lumen gentium parle de l'infaillibilité en ces termes : « Cette infaillibilité, le pontife romain la possède en vertu de son office lorsque, en sa qualité de pasteur et de docteur suprême de tous les fidèles qui confirme dans la foi ses frères, il proclame, en la définissant, une doctrine de foi ou de morale. [...] Lorsque le pontife romain ou le corps des évêques avec lui définissent une vérité, ils l'entendent selon la révélation elle-même, à laquelle tous doivent adhérer et se conformer " (Ibid., p. 766). Autrement dit, la révélation, «telle qu'elle nous est parvenue dans le depositum qui nous est transmis, reste le point de référence permanent» (Ibid., p. 768). Le concile Vatican I précise enfin « qu'il faut rejeter l'opinion selon laquelle toute proclamation pontificale (encyclique, instruction, etc.) serait une expression du magistère infaillible» (Ibid., p. 768). 
${ }^{113}$ Paul Christophe, L'Église dans l'bistoire des hommes du quinzième siècle à nos jours, tome 2, Limoges, Droguet-Ardant, 1983, p. 579.

${ }^{114}$ Marcel Marcotte, "L'encyclique Humana Vita et l'obéissance catholique ", Relations, vol. 28, $\mathrm{n}^{\circ} 330$ (septembre 1968), p. 249.

${ }^{115}$ André Charbonneau, Pierre Saucier, Hélène Pelletier-Baillargeon, « Les couples catholiques après l'encyclique », Maintenant, $\mathrm{n}^{\circ} 79$ (août-septembre 1968), pp. 196-199.

${ }^{116}$ Hélène Pelletier-Baillargeon, "Qui est le nouveau directeur ? ", Maintenant, vol. 4 (automne 1965), p. 262.

${ }^{117}$ Henri Madelin, "Comment peut-on être jésuite en 2002 ?", propos recueillis par Jérôme Cordelier, Le Point (25 avril 2002), p. 78.

${ }^{118}$ Vincent Harvey, «Survol d'une évolution », Maintenant, $\mathrm{n}^{\circ} 60$ (décembre 1966), p. 381.

${ }^{119}$ Ibid., p. 382.

${ }^{120}$ Ibid., p. 383.

${ }^{121}$ Ibid., p. 383.

${ }^{122}$ Ibid., p. 384.

${ }^{123}$ Marcel Marcotte, «Le Cardinal au Concile plaide la cause de l'amour », Relations, vol. 24, nº 288 (décembre 1964), p. 349.

${ }^{124}$ Ibid., p. 349.

${ }^{125}$ Ibid., p. 349.

${ }^{126}$ Ibid., p. 352.

${ }^{127}$ Ibid., p. 385.

${ }^{128}$ Jean Hamelin, Histoire du catholicisme québécois, vol. 3, Le XX' siècle, tome 2, De 1940 à nos jours, Montréal, Boréal Express, 1984, p. 330.

${ }^{129}$ Simonne Monet-Chartrand, Le Devoir, 6 août 1968, p. 11, reproduit dans Hamelin, Histoire du catbolicisme québécois, tome 2, p. 331.

${ }^{130}$ Ibid., p. 332.

${ }^{131}$ Marcel Marcotte, «L'encyclique Humana Vita et l'obéissance catholique », Relations, vol. 28, n 330 (septembre 1968), p. 245.

${ }^{132}$ Ibid., p. 245. 
${ }^{133}$ Ibid., p. 247.

${ }^{134}$ Ibid., p. 247.

${ }^{135}$ Marcel Marcotte, «L'encyclique Humana Vita, et la liberté de conscience », Relations, vol. 28, n 333 (décembre 1968), p. 340.

${ }^{136}$ Ibid., p. 304.

${ }^{137}$ Ibid., p. 304.

${ }^{138}$ David Seljak, "Catholicism's Quiet Revolution : Maintenant and the New Public Catholicism in Quebec after 1960 ", St. Jerome University, August 1999, p. 12. Exemplaire dactylographié d'un article publié dans Marguerite Van Die, dir., Religion and Public Life in Canada: Historical and Comparative Perspectives, Toronto, University of Toronto Press, 2001, pp. 257-274.

${ }^{139}$ "Humana Vita », Maintenant, $\mathrm{n}^{\circ} 79$ (15 août - 15 septembre 1968), pp. 195196.

${ }^{1+1)}$ André Charbonneau, Pierre Saucier, Hélène Pelletier-Baillargeon, « Les couples catholiques après l'encyclique », Maintenant, $\mathrm{n}^{\circ} 79$ (15 août - 15 septembre 1968), p. 197.

${ }^{141}$ Ibid., p. 199.

${ }^{1+2}$ Ibid., p. 197.

${ }^{143}$ Ibid., p. 199.

${ }^{144}$ Ibid., p. 204.

${ }^{145}$ Luigi d'Apollonia, «Vicaire du Christ », Relations, vol. 28, n 330 (septembre 1968), p. 244.

${ }^{146}$ H.-M. Bradet, « Sommes-nous engagés ? », Maintenant, vol. 1 (mai 1962), p. 159.

${ }^{147}$ Henri Dallaire, « Notre presse : catholique ou libre?", Maintenant, vol. 1 (mai 1962), p. 171. «L'alternative est fausse, écrit le père Dallaire : une presse libre pourrait fort bien se vouloir catholique ; et par contre, une presse catholique peut jouir de la plus entière liberté ».

${ }^{148}$ Beausoleil, op. cit., p. 107.

14) Gilles Routhier, "Vatican II n'est pas terminé », La Presse (10 octobre 2002), p. A13.

${ }^{150}$ Ibid. 